\title{
Low molecular weight chitosan nanoparticulate system at low N:P ratio for nontoxic polynucleotide delivery
}

This article was published in the following Dove Press journal:

International Journal of Nanomedicine

12 March 2012

Number of times this article has been viewed

\section{Mohamad Alameh \\ Diogo Dejesus \\ Myriam Jean \\ Vincent Darras \\ Marc Thibault \\ Marc Lavertu \\ Michael D Buschmann \\ Abderrazzak Merzouki \\ Institute of Biomedical Engineering, Department of Chemical Engineering, École Polytechnique, Montréal, Canada}

Correspondence: Abderrazzak Merzouk Institute of Biomedical Engineering, Department of Chemical Engineering, École Polytechnique, PO Box 6079, Station Centre-ville, Montréal (Québec), Canada $\mathrm{H} 3 \mathrm{C} 3 \mathrm{~A} 7$

$\mathrm{Tel}+|5| 4340512 \mid$ ext 4799

$\mathrm{Fax}+\mathrm{I} 5143405227$

Email abderrazzak.merzouki@polymtl.ca
Abstract: Chitosan, a natural polymer, is a promising system for the therapeutic delivery of both plasmid DNA and synthetic small interfering RNA. Reports attempting to identify the optimal parameters of chitosan for synthetic small interfering RNA delivery were inconclusive with high molecular weight at high amine-to-phosphate $(\mathrm{N}: \mathrm{P})$ ratios apparently required for efficient transfection. Here we show, for the first time, that low molecular weight chitosan (LMW-CS) formulations at low N:P ratios are suitable for the in vitro delivery of small interfering RNA. LMW-CS nanoparticles at low N:P ratios were positively charged ( $\zeta$-potential $\sim 20 \mathrm{mV}$ ) with an average size below $100 \mathrm{~nm}$ as demonstrated by dynamic light scattering and environmental scanning electron microscopy, respectively. Nanoparticles were spherical, a shape promoting decreased cytotoxicity and enhanced cellular uptake. Nanoparticle stability was effective for at least 20 hours at $\mathrm{N}: \mathrm{P}$ ratios above two in a slightly acidic $\mathrm{pH}$ of 6.5 . At a higher basic $\mathrm{pH}$ of 8 , these nanoparticles were unravelled due to chitosan neutralization, exposing their polynucleotide cargo. Cellular uptake ranged from $50 \%$ to $95 \%$ in six different cell lines as measured by cytometry. Increasing chitosan molecular weight improved nanoparticle stability as well as the ability of nanoparticles to protect the oligonucleotide cargo from nucleases at supraphysiological concentrations. The highest knockdown efficiency was obtained with the specific formulation 92-10-5 that combines sufficient nuclease protection with effective intracellular release. This system attained $>70 \%$ knockdown of the messenger RNA, similar to commercially available lipoplexes, without apparent cytotoxicity. Contrary to previous reports, our data demonstrate that LMW-CS at low N:P ratios are efficient and nontoxic polynucleotide delivery systems capable of transfecting a plethora of cell lines.

Keywords: siRNA, nonviral delivery system, chitosan, gene silencing, RecQL1, ApoB

\section{Introduction}

RNA interference (RNAi), an evolutionary endogenous gene regulation mechanism based on double-stranded RNA (short hairpin RNA, microRNA, Piwi-interacting RNA, and small interfering RNA [siRNA]), has provided a potential new class of therapeutics. ${ }^{1}$ Since its discovery in Caenorhabditis elegans, ${ }^{2}$ RNAi has been proven effective in mammalian cells ${ }^{1,3-11}$ and has reached clinical trials. ${ }^{1,12-14}$ However, direct delivery of RNAi-inducing entities such as synthetic siRNA or short hairpin RNA continues to be problematic owing to their rapid extracellular/intracellular degradation by nucleases (ie, RNAse and DNAse), limited blood stability, poor cellular uptake, and nonspecific targeting. ${ }^{15-17}$ As a consequence, the translation of RNAi into a clinical therapeutic reality is still pending resolution of these issues. 
Chemical modification of synthetic siRNAs has provided resistance to nuclease degradation and improved blood stability. ${ }^{18-22}$ For example, selective addition of a phosphorothioate linkage or substitution with 2'-O-methyl on the $\mathrm{C} 2$ position of specific riboses increases nuclease resistance of siRNAs without compromising activity..$^{14,19,20}$ Nevertheless, some chemical modifications can increase cytotoxicity, off-target effects and reduce messenger RNA (mRNA) hybridization. ${ }^{23-27}$ Despite progress achieved through chemical modification to increase siRNA half-life, transfection efficiency, cellular targeting, and uptake remain as obstacles to effective delivery. Therefore, packaging systems which can both protect and transport chemically unmodified/modified siRNA to target cells are required.

Liposomes/Lipoplexes have been extensively used as nonviral vehicles for plasmid and RNAi entities and pose toxicity concerns. For example, the repeated administration of lipid-based delivery vehicles caused phospholipidosis. ${ }^{28}$ Intravenous injection of stable nucleic acid-lipid particles has successfully targeted the liver to silence the apolipoprotein $B(A p o B)$ gene in mice and nonhuman primates. ${ }^{10}$ However, a significant 20-fold transient elevation in serum transaminases (aspartate transaminase, alanine transaminase) indicative of hepatocellular necrosis was identified at the effective dose. Liposomal formulations of nucleic acids are known inducers of inflammatory cytokines including tumor necrosis factor-alpha, interferon-gamma, and interleukin-6 which may be related to liver damage. ${ }^{29}$ Polyethylene glycol (PEG) modification of liposomes (PEGylation), for the purpose of reducing their toxicity, was also demonstrated to elicit acute hypersensitivity after repeated dosing. ${ }^{30-32}$ Similarly, the highly studied cationic family of polymers such as polyethylenimine demonstrated high gene transfer efficiency but was also associated with significant toxicity issues ${ }^{1,33}$ limiting their broad use in clinical trials. Polyethylenimine cytotoxicity was characterized as a two-phase process where the polycation-cell interaction induces loss of cell membrane integrity and the induction of programmed cell death. Insights into polyethylenimine toxicity highlight the importance of polycation/organelle interactions - ie, mitochondria and lysosomes - on the induction of toxicity. ${ }^{34,35}$ In general, cationic polymers display less toxicity associated with cytokine induction - immune activation - compared to their cationic lipid counterparts. ${ }^{36}$

Chitosan, a family of cationic polymers of $\beta-1-4 \mathrm{~N}$-acetylglucosamine and D-glucosamine residues, has been extensively studied for the delivery of plasmid DNA (pDNA) and siRNA both in vitro and in vivo. ${ }^{3,8,17,37-43}$ Chitosan properties include mucoadhesivity, ${ }^{44}$ biocompatibility, biodegradability, ${ }^{45}$ nontoxicity, and low cost of production. Primary amine residues confer a polycationic nature to chitosan at $\mathrm{pH}$ values below its $\mathrm{pKa}(\sim 6.5)$ thus enabling it to condense polyanionic compounds such as nucleic acids. Electrostatic interaction between chitosan and nucleic acids leads to the spontaneous formation of nanoparticles of different sizes and shapes. ${ }^{46}$ The ability of chitosan-based nanoparticles to transfect cells efficiently depends on several parameters such as: (1) the degree of deacetylation (DDA), which represents the fraction of ionizable monomers; (2) the average molecular weight $\left(M_{\mathrm{n}}\right)$, proportional to chain length, and (3) the amine-to-phosphate (N:P) charge ratio represented by the amine-(chitosan)-to-phosphate (DNA or RNA) ratio used to form nanoparticles.

We have previously demonstrated that maximization of in vitro transfection efficiency for the delivery of pDNA depends on a fine balance between these tunable parameters of chitosan ${ }^{38-40}$ and found maximum transgene expression for DDA: $M_{\mathrm{n}}$ values that run along a diagonal from high DDA/ low $M_{\mathrm{n}}$ to low DDA/high $M_{\mathrm{n}}{ }^{38}$ We have also demonstrated that specific chitosan formulations [DDA, $M_{\mathrm{n}}$, and N:P ratio] efficiently express transgene in vivo. ${ }^{37,41}$

We also demonstrated that specific formulations are able to trigger an anti-transgene immune response, ${ }^{37}$ therefore, nanoparticles can be designed based on the fine-tuning of chitosan parameters for application-specific purposes such as genetic vaccination or gene therapy.

The structural differences between pDNA and siRNA are believed to affect the complexation/stability of nanoparticles and optimal parameters required for effective delivery. Chitosan has also been used for siRNA delivery both in vitro and in vivo. ${ }^{1,8,10,17,43}$ However, and despite attempts to identify optimal physicochemical parameters for siRNA delivery, ${ }^{43}$ inconclusive results have been observed in the literature due to experimental discrepancies. ${ }^{8,17}$ For example, it was reported that intermediate DDA $(80 \%)$ and high $\mathrm{Mw}(64-170 \mathrm{kDa})$ chitosan were more efficient than low molecular weight chitosan (LMW-CS) (10 kDa) in delivering siRNA. ${ }^{17,43}$ However, high molecular weight chitosans are found to be cytotoxic, ${ }^{47-49}$ thus potentially limiting their use in future clinical trials. Additionally, most of the reports evaluating the physicochemical parameters of chitosan/siRNA nanoparticles were performed at high N:P ratios $(\mathrm{N}: \mathrm{P}>25) .{ }^{8,17,43}$ Such formulations bring significant practical problems including limited dosing due to aggregation and the nonspecific effects of large quantities of soluble chitosan. ${ }^{50}$ Here, we investigate, for the first time, the ability 
of specific LMW-CS formulations (92-10-5, 80-80-10, 80-40-5, and 80-10-10) [DDA, $M_{\mathrm{n}}$, and N:P ratio] at low $\mathrm{N}$ :P ratios to in vitro deliver siRNA targeting: (1) the RecQL1 DNA helicase mRNA in the colon adenocarcinoma RecQL1 overexpressing cell line (LS174T) and (2) ApoB mRNA in the hepatocarcinoma-derived cell line (HepG2). The choice of these two targets resides in their relevance to cancer and atherosclerosis, respectively. ${ }^{6,7,9,51,52}$ We also explored the ability of these formulations to transfect multiple cell lines such as A549, AsPC1, HEK293, and Raw264.7 without apparent toxicity. In this study, we hypothesized that, contrary to previous literature, ${ }^{8,17,42,43}$ low Mw chitosans (LMW-CS) complexed at low $\mathrm{N}: \mathrm{P}$ ratios represent suitable formulations for siRNA delivery and gene knockdown; similar to our observations with pDNA. ${ }^{37-41}$ Additionally, we hypothesized that low $\mathrm{N}: \mathrm{P}$ ratios assure sufficient protection and efficient delivery of the siRNA cargo. Moreover, we explore the physicochemical properties of these specific formulations with the prospect of optimizing nanoparticle transfection and silencing efficiencies. Our results demonstrate, for the first time, that LMW-CSs at low N:P ratios are effective and nontoxic delivery systems for polynucleotide and siRNA delivery for in vitro gene silencing.

\section{Materials and methods Synthesis of siRNAs and dsODNs}

siRNAs targeting the RecQL1 DNA helicase and ApoB mRNAs were synthesized using a novel RNA synthesis chemistry, the $5^{\prime}$-silyl- $2^{\prime}$-orthoester protecting groups $\left(2^{\prime} \text {-ACE }\right)^{54}$ combined with a standard phosphoramitide solid-phase technology by Dharmacon (Thermo Scientific, Dharmacon RNAi Technologies, Lafayette, CO). RecQL1 mRNA-specific siRNA (siRNA-RecQL1) contains the sense sequence of 5'-GUUCAGACCACUUCAGCUUdTdT-3' and antisense 5'-AAGCUGAAGUGGUCUGAACdTdT-3' whereas ApoB mRNA-specific siRNA (siRNA-ApoB) contains the sense sequence of 5'-GUCAUCACACUGAAUACCAAU-3' and antisense 5'-AUUGGUAUUCAGUGUGAUGACAC-3' Mock siRNA was also used as a negative control. Mock siRNA is a nontargeting siRNA (Dharmacon, D-001710-01-05) designed to have minimal targeting of known genes in human, mouse, and rat cells.

Double-stranded oligodeoxynucleotides (dsODNs, $21 \mathrm{bp}$ ) encoding the same sequences and mimicking siRNA physicochemical properties were used for nanoparticle characterization. The double-stranded oligodeoxynucleotide (dsODN) sequences were synthesized using the phosphoramidite chemistry (Integrated DNA
Technologies Inc, Coralville, IO) and used for size and zeta potential determination, nanoparticle stability, and nuclease protection assays. For confocal microscopy and flow cytometry analysis, 6-carboxyfluorescein (6FAM) 5'-labeled dsODNs were used (Integrated DNA Technologies Inc). The rationale for using dsODN for chitosan nanoparticle physicochemical characterization is their siRNA-mimicking properties. These mimicking properties are due to similarities at the structural level (double-stranded structure, length, and nucleotide overhangs) between siRNA and dsODNs. Additionally, charge densities are similar between siRNA and dsODNs due to identical phosphate residue numbers on their backbone. The main differences between siRNA and dsODNs lie in the substitution of uracil to thymine $(U \rightarrow T)$ in the dsODN sequences, and in the deoxyribosilation of the dsODN sugar backbone.

\section{Preparation and characterization of depolymerized chitosan}

Clinical-grade chitosan at different DDAs was obtained from BioSynthec Inc, (Laval, QC, Canada) and depolymerized using nitrous acid to achieve specific number-average molecular weight targets $\left(M_{\mathrm{n}}\right)$ of 80,40 , and $10 \mathrm{kDa}$. Chitosan number- and weight-average molecular weights $\left(M_{\mathrm{n}}\right.$ and $\left.M_{\mathrm{w}}\right)$ were determined by gel permeation chromatography using a Shimadzu LC-20AD isocratic pump, autosampler SIL-20AC HT, oven CTO-20AC coupled with a Dawn HELEOS II multiangle laser light scattering detector (Wyatt Technology Co, Santa Barbara, CA), a Viscostar II (Wyatt Technology Co), an Optilab rEX interferometric refractometer (Wyatt Technology Co), and two Shodex OHpak (SB-806M HQ and SB-805 HQ; Showa Denko America, Inc, New York, NY) columns eluted with a $\mathrm{pH} 4.5$ acetic acid $(0.15 \mathrm{M})$ /sodium acetate $(0.1 \mathrm{M})$ /sodium azide (4 mM) buffer. ${ }^{54,55}$ The injection volume was $100 \mu \mathrm{L}$, the flow rate $0.8 \mathrm{~mL} \mathrm{~min}^{-1}$ and the temperature $25^{\circ} \mathrm{C}$. The $\mathrm{dn} / \mathrm{dc}$ value was previously calculated for chitosan with a DDA of $92 \%$ (for a laser's wavelength of $658 \mathrm{~nm}$ ) and is equal to 0.208 and 0.201 for chitosan with $80 \%$ DDA. The degree of deacetylation was determined by ${ }^{1} \mathrm{H}$ NMR according to our previous reports..$^{38,56}$

\section{Preparation of chitosan nanoparticles}

Chitosans with specific $M_{\mathrm{n}}$ and DDA (Table 1) were dissolved overnight on a rotary mixer at $0.5 \%(\mathrm{w} / \mathrm{v})$ in hydrochloric acid using a glucosamine: $\mathrm{HCl}$ ratio of $1: 1$ at a final concentration of $5 \mathrm{mg} / \mathrm{mL}$. Sterile filtered solutions were then diluted with deionized water to obtain the desired ratio 
Table I Physicochemical characteristics of bulk chitosans

\begin{tabular}{|c|c|c|c|c|c|}
\hline Chitosan & DDA (\%) ${ }^{a}$ & $M_{n}(\mathrm{kDa})^{\mathrm{b}}$ & $M_{w}(k D a)$ & PDI ${ }^{c}$ & N:P ratio \\
\hline $92-10$ & 92 & 10 & 11.8 & 1.5 & 5 \\
\hline $80-10$ & 80 & 10 & 14.5 & 1.3 & 10 \\
\hline $80-40$ & 80 & 40 & 53.0 & 1.3 & 5 \\
\hline $80-80$ & 80 & 80 & 110.9 & 1.6 & 5 \\
\hline
\end{tabular}

Notes: ${ }^{a}$ As determined by IH NMR; bas determined by gel permeation chromatography (GPC); ' $M_{w} / M_{n}$; 'nanopartice N:P ratio follwing complexation with either dsODN or siRNA used in this study.

Abbreviations: DDA, degree of deacetylation; $M_{n}$, number average molecular weight; $M_{w^{\prime}}$, specific molecular weight; PDI, polydispersity index; N:P, amine to phosphate; dsODN, double-stranded oligodeoxynucleotides.

(N:P) of amine (chitosan deacetylated groups) to phosphate (dsODNs/siRNA nucleic acids). Nanoparticles (92-10-5, $80-10-10,80-40-5$, and 80-80-5) were then prepared by rapid mixing (pipetting) of $100 \mu \mathrm{L}$ of diluted chitosan solution to $100 \mu \mathrm{L}$ of dsODNs or siRNA at a concentration of $0.05 \mu \mathrm{g} / \mu \mathrm{L}$ or $100 \mathrm{nM}$.

\section{Nanoparticle size and $\zeta$-potential analysis}

The size of chitosan/dsODN-RecQL1 and chitosan/dsODNApoB nanoparticles - intensity average diameter - was determined by dynamic light scattering at an angle of $173^{\circ}$ at room temperature using the Malvern Zetasizer Nano ZS (Malvern, Worcestershire, UK). Following nanoparticle formation, samples were diluted in $10 \mathrm{mM} \mathrm{NaCl}$ at a ratio of $1: 10$ and measured in triplicate. The $\zeta$-potential was measured in triplicate using laser Doppler velocimetry at $25^{\circ} \mathrm{C}$ on the same instrument with the viscosity and dielectric constant of pure water used for calculations.

\section{Environmental scanning electron microscopy (ESEM)}

Chitosan/dsODN-RecQL1 and chitosan/dsODN-ApoB nanoparticles were sprayed on silicon wafer substrate then sputtercoated with gold (Agar Manual Sputter Coater; Marivac Inc, Montreal, QC, Canada) and imaged using a Quanta 200 FEG Environmental Scanning Electron Microscope (FEI Inc, Hillsboro, OR). Observations were performed at $20 \mathrm{kV}$ using the high-vacuum mode. The average particle diameter ( \pm standard deviation) was determined using the XT Docu image analysis software (FEI Inc).

\section{Nanoparticle stability assessment by polyacrylamide gel electrophoresis}

The stability of chitosan/dsODN nanoparticles at different pHs (6.5 and 8) and for different incubation times $(0.5,4$, and 24 hours) was assessed using polyacrylamide gel electrophoresis. Upon formation, nanoparticles were mixed at a ratio of 1:1 with 2-(N-morpholino)ethanesulfonic acid buffer (MES 1X) (20 mM MES, 8 mM sodium acetate, pH 6.5) or Tris-acetate (TAE)-EDTA buffer (TAE $1 \mathrm{X})$ ( $2 \mathrm{M}$ Tris-acetate, $50 \mathrm{mM}$ EDTA, $\mathrm{pH}$ 8). The samples were then migrated on a $13 \%$ polyacrylamide gel (BioRad Laboratories, Mississauga, ON, Canada) for 2 hours at $100 \mathrm{mV}$ in either MES or TAE buffer. Gels were stained with $0.5 \mu \mathrm{g} / \mathrm{mL}$ ethidium bromide solution (BioRad Laboratories) to visualize dsODNs. Gel documentation and image analysis were performed using a Bio-Vision 3000 (Vilbert Lourmat, Marne-la-Vallée, France) and the Vision-Capt software, respectively.

\section{Nuclease protection assay}

The level of protection against nuclease attack offered by chitosan formulations (92-10-5, 80-80-10, 80-40-5, and $80-80-5)$ was assessed electrophoretically on a $5 \%$ agarose gel. Chitosan/dsODN-RecQL1 and chitosan/dsODN-ApoB nanoparticles at different DDA, $M_{\mathrm{w}}$, and N:P ratios were incubated with $0.5,1,2,5$, or 10 units of DNAse I (SigmaAldrich, Oakville, ON, Canada) per $\mu \mathrm{g}$ of dsODNs in $20 \mu \mathrm{L}$ of MES- $\mathrm{MgCl}_{2}$ buffer (20 mM MES, $1 \mathrm{mM} \mathrm{MgCl}$, $\mathrm{pH}$ 6.5) for 30 minutes at $37^{\circ} \mathrm{C}$. The reaction was stopped by adding $2 \mu \mathrm{L}$ of EDTA ( $50 \mathrm{mM}$ ) (Sigma-Aldrich). To ensure proper migration of the nondigested dsODNs, samples were treated with Streptomyces griseus type III chitosanase (Sigma-Aldrich) at $10 \mathrm{mU} / \mu \mathrm{L}$ for 1.5 hours at $37^{\circ} \mathrm{C}$ and stopped by placing the samples at $-20^{\circ} \mathrm{C}$ for 15 minutes as previously described. ${ }^{3}$ Samples were migrated at $90 \mathrm{~V}$ during 1 hour then stained with $0.5 \mu \mathrm{g} / \mathrm{mL}$ ethidium bromide solution before visualization. Captured images were analyzed using Vision-Capt software (v 15.06; Vilber Lourmat, Paris, France). Relative amounts of dsODN-RecQL1 or dsODN-ApoB (\%) were determined by comparison of the integrated signal intensity of nucleasetreated samples versus nontreated samples.

\section{In vitro cell transfection}

Cell culture

All cell lines were purchased from American Type Cell Culture (Manassas, VA). The HepG2 cell line was cultured in minimal essential medium (MEM). The HEK293, Raw294.7, and LS174T cell lines were cultured in high-glucose Dulbecco's modified eagle's media (DMEM-HG). The A549 and AsPC1 cell lines were cultured in F12-K and Roswell Park Memorial Institute medium media, respectively. All cell culture media contained $1.85 \mathrm{~g} / \mathrm{L}$ of sodium bicarbonate $\left(\mathrm{NaHCO}_{3}\right)$ and were supplemented with $10 \%$ fetal bovine serum (Cedarlane Laboratories, Burlington, ON, Canada). 
All cell lines were cultured at $37^{\circ} \mathrm{C}$ in a $5 \% \mathrm{CO}_{2}$ incubator. For transfection, cells were plated in 96-well or 24-well culture plates (Corning, Lowell, MA) to obtain a $\sim 50 \%$ confluence the day of transfection using $100 \mu \mathrm{L} /$ well or $500 \mu \mathrm{L} /$ well, respectively, of complete culture medium.

\section{Cell transfection}

For in vitro transfection, DMEM-HG was prepared with $0.976 \mathrm{~g} / \mathrm{L}$ of MES and $0.84 \mathrm{~g} / \mathrm{L}$ of $\mathrm{NaHCO}_{3}$ at a pH of 6.5 . Transfection media containing $10 \%$ fetal bovine serum was equilibrated overnight at $37^{\circ} \mathrm{C}$ in a $5 \% \mathrm{CO}_{2}$ incubator and the $\mathrm{pH}$ was adjusted to 6.5 using sterile $\mathrm{HCl}(1 \mathrm{~N})$ prior to transfection. For siRNA transfection performed in a 96-well plate, chitosan/siRNA nanoparticles were prepared as described above, 30 minutes before use. A $100 \mu \mathrm{L}$ siRNA solution at a concentration of $0.05 \mu \mathrm{g} / \mu \mathrm{L}$ was used for siRNA complexation with chitosan at a 1:1 ratio (v/v). Following complexation, nanoparticles were incubated in a ghost plate containing the transfection media (DMEM-HG + fetal bovine serum) at a final concentration of $1.35 \mathrm{ng} / \mu \mathrm{L}$; equivalent to 10 pmol per well of siRNA. For dsODN transfection performed in a 24-well plate, nanoparticles were complexed as described above and incubated at a final concentration of $8.07 \mathrm{ng} / \mu \mathrm{L}$, equivalent to $60 \mathrm{pmol}$ per well of dsODNs. Plates containing nanoparticles were equilibrated for $10 \mathrm{~min}$ utes at $37^{\circ} \mathrm{C}, 5 \% \mathrm{CO}_{2}$. Medium over cells was aspirated and replenished with either $500 \mu \mathrm{L}$ (24-well plate) or $100 \mu \mathrm{L}$ per well (96-well plate) of the transfection medium containing dsODN-or siRNA-based nanoparticles. Cells were incubated with chitosan/siRNA or chitosan/dsODN nanoparticles until analysis 24 hours post transfection. The commercially available liposome, DharmaFECT ${ }^{\mathrm{TM}}$ (Dharmacon RNAi Technologies), was used as a positive control and both untreated cells and uncomplexed siRNA/dsODN-treated cells were used as negative controls.

\section{Transfection with DharmaFECT}

DharmaFECT was used as a positive control for transfection efficiency in all tested cell lines. DharmaFECT/dsODN (flow cytometry and confocal microscopy) or DharmaFECT/ siRNA (qPCR and viability assay) lipoplexes (1:2 [w/v] ratio) were prepared following the manufacturer's protocol.

\section{In vitro cell viability assay}

Nanoparticle toxicity was evaluated using the alamarBlue ${ }^{\circledR}$ proliferation assay (Invitrogen, Carlsbad, CA). The principle of the assay is based on the natural reducing power of viable cells to convert resazurin, a blue and nonfluorescent compound, into resofurin; a red and fluorescent molecule. Viable cells continuously convert resazurin to resofurin, thereby providing a quantitative measure of viability. Transfection was performed as described above using chitosan-siRNA nanoparticles. Five thousand cells/well were seeded 24 hours before transfection. To alleviate the experimental bias from the effect of RecQL1 gene silencing on cell viability, nontargeting siRNA (siRNA mock) was used instead. Twenty-four hours post transfection with chitosan-based nanoparticles, $20 \mu \mathrm{L}$ of alamarBlue reagent, pre-warmed at $37^{\circ} \mathrm{C}$ was added to each well and incubated for another 4 hours. At the end of the incubation $100 \mu \mathrm{L}$ of media containing reduced alamarBlue dye was transferred to a black Corning 96-well plate and read on an infinite 200 fluorescence plate reader (Tecan Systems, San Jose, CA) with excitation $560 \mathrm{~nm}$, emission $590 \mathrm{~nm}$ and a cut-off of $570 \mathrm{~nm}$. Cells without the addition of alamarBlue were used as blank and dimethyl sulfoxide was used as a positive control of toxicity. The viability of nontransfected control cells was arbitrarily defined as $100 \%$. The relative cell viability was calculated using the following formula: (fluorescence intensity $_{\text {sample }} /$ fluorescence intensity $\left._{\text {control }}\right) \times 100$. $^{2}$

\section{Uptake analysis by flow cytometry and confocal microscopy}

Fluorescence-activated cell sorting (FACS) analysis

The cellular uptake of dsODNs was determined by transfecting AsPC1, A549, LS174T, HepG2, HEK293, and Raw264.7 cell lines with nanoparticles formed with (6FAM) 5'labeled dsODNs. Twenty-four hours post-transfection, cells were chitosanase treated for 60 minutes to eliminate any cell surface-associated nanoparticles left from the transfection as described previously. ${ }^{3}$ Afterward, cells were washed twice with phosphate-buffered saline, trypsinized, and resuspended in phosphate-buffered saline. The analysis of cell uptake was made using a BD Canto flow cytometer (Becton Dickinson, San Jose, CA). For each sample, 20,000 events were counted and to exclude cell debris, dead cells, and aggregated cells, a collection gate was established using a dot plot of the forward light scatter against the side scatter. Nontransfected cells were used as negative controls to discriminate (6FAM) positive cells from auto-fluorescence.

\section{Confocal microscopy}

For nanoparticle internalization analysis, the LS174T, HepG2, HEK293, and Raw264.7 cell lines were seeded on $35 \mathrm{~mm}$ glass-bottom culture dishes (MatTek, Ashland, MA) at 40,000 cells/dish using $500 \mu \mathrm{L}$ of complete culture medium. 
Nanoparticles were formed with fluorescent rhodamine B isothiocyanate-labeled chitosan and dsODNs labeled with 6FAM on their $5^{\prime}$ extremities (Integrated DNA Technologies). Prior to imaging, cell membranes were stained with $5 \mu \mathrm{g} / \mathrm{mL}$ of Cell Mask ${ }^{\mathrm{TM}}$ Deep Red (Invitrogen, Burlington, ON, Canada). Images were taken in multitrack mode using a Zeiss LSM 510 META confocal Axioplan 200 microscope (Carl Zeiss AG, Feldbach, Switzerland). Chitosan and dsODNs were visualized as red and green pseudocolors, respectively. The spatial overlap of these two colors produced yellow which permitted a qualitative assessment of colocalization.

\section{Quantitative PCR (qPCR) analysis of RecQLI and ApoB mRNA knockdown} RNA extraction and assessment methods (yield, purity, and integrity)

RNA extraction was performed using the RNA XS ${ }^{\circledR}$ extraction kit from Macherey-Nagel (Biolynx, Montréal, QC, Canada) according to the manufacturer's protocol following chitosanase treatment, as described previously. ${ }^{3}$ Total RNA was quantified and RNA integrity was measured using the Agilent BioAnalyzer 2100 (Agilent Technologies, Mississauga, ON, Canada) following the manufacturer's protocol. RNA integrity was evaluated by the ratio of $28 \mathrm{~S} / 18 \mathrm{~S}$ ribosomal RNA $^{57}$ and the RNA integrity number (RIN). The Agilent 2100 BioAnalyzer uses automated microfluidics, capillary electrophoresis, and fluorescence to evaluate RNA integrity. The RIN is a relative measure of RNA quality that is based largely on electrophoretic trace analysis. The BioAnalyzer 2100 automatically computes RIN, where an ideal nondegraded RNA sample has RIN $=10$.

\section{Reverse transcription}

Total RNA was reverse transcribed in a final volume of $20 \mu \mathrm{L}$ using the First Strand cDNA Transcriptor Kit (Roche Diagnostics, Laval, QC, Canada) with oligodT primers as described by the manufacturer's protocol. Samples were stored at $-20^{\circ} \mathrm{C}$.

\section{Gene expression assays}

The RecQL1 and ApoB mRNA expression level was determined using assays designed with the Universal Probe Library (UPL) from Roche (Roche Applied Science, Laval, QC, Canada). Endogenous control (hypoxanthine guanine phosphoribosyl transferase) and glyceraldehyde 3-phosphate dehydrogenase expression levels were determined using pre-validated TaqMan ${ }^{\circledR}$ Gene Expression Assays
(Applied Biosystems, Carlsbad, CA). RecQL1 and ApoB mRNA (target detection) reactions for 384-well plate formats were performed using 1.5 $\mathrm{L}$ of cDNA samples (25-50 ng), $5 \mu \mathrm{L}$ of the Fast Universal qPCR MasterMix (Applied Biosystems) $2 \mu \mathrm{M}$ of each primer, and $1 \mu \mathrm{M}$ of a Universal Probe Library probe (RecQL1 [probe \#29]/ApoB [probe \#55]) in a total volume of $10 \mu \mathrm{L}$. For endogenous control assessment, reactions were performed using identical volumes of cDNA and, Fast Universal qPCR Master Mix, $0.5 \mu \mathrm{L}$ of the TaqMan Gene Expression Assay (20×) and $2.5 \mu \mathrm{L}$ of water in a total volume of $10 \mu \mathrm{L}$.

\section{Detection and analysis}

The ABI PRISM ${ }^{\circledR} 7900 H T$ Sequence Detection System (Applied Biosystems) was used to detect the amplification level and was programmed with an initial step of 3 minutes at $95^{\circ} \mathrm{C}$, followed by 45 cycles of 5 seconds at $95^{\circ} \mathrm{C}$ and 30 seconds at $60^{\circ} \mathrm{C}$. All reactions were run in triplicate and the average values of $\mathrm{Cts}$ (threshold cycle) were used for quantification. Glyceraldehyde 3-phosphate dehydrogenase and hypoxanthine guanine phosphoribosyl transferase were used as endogenous controls. The relative quantification of target genes was determined using the $\rho \rho C T$ method. Briefly, the $\mathrm{Ct}$ values of target genes were normalized to an endogenous control gene (endogenous control) $\left(\Delta \mathrm{CT}=\mathrm{Ct}_{\text {target }}-\mathrm{Ct}_{\text {endoC }}\right)$ and compared with a calibrator: $\Delta \Delta \mathrm{CT}=\Delta \mathrm{Ct}_{\text {target }}-\Delta \mathrm{Ct}_{\text {calibrator }}$. Relative expression (RQ) was calculated using the Sequence Detection System 2.2.2 software using the $\mathrm{RQ}=2^{-\Delta \Delta \mathrm{CT}}$ formula.

\section{Statistical analysis}

The statistical analysis was performed using Statistica 9.0 Software (STATSOFT; Statistica, Tulsa, OK). Data are expressed as mean \pm standard deviation. Statistical significance was determined with one-way analysis of variance, followed by Tukey's post hoc test. The results were considered significant and highly significant $(P<0.05$ and $P<0.01$, respectively).

\section{Results \\ Size and $\zeta$-potential of chitosan nanoparticles}

All formulations of chitosan/dsODN nanoparticles were in the range of 41-109 nm as measured by environmental scanning electron microscopy (ESEM) and dynamic light scattering (Figure 1 and Table 2). Chitosan/dsODN nanoparticles showed higher size values with increasing $M_{\mathrm{n}}$. No statistically significant differences were observed when comparing DDAs 


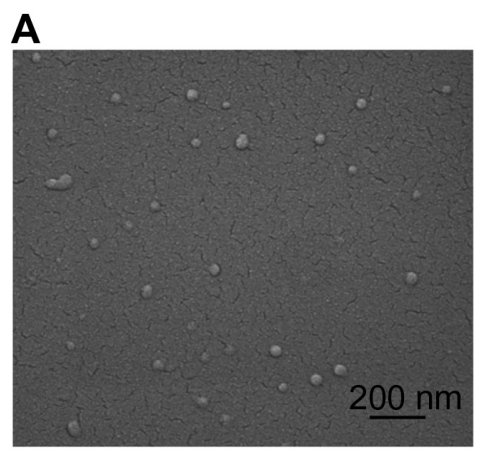

D

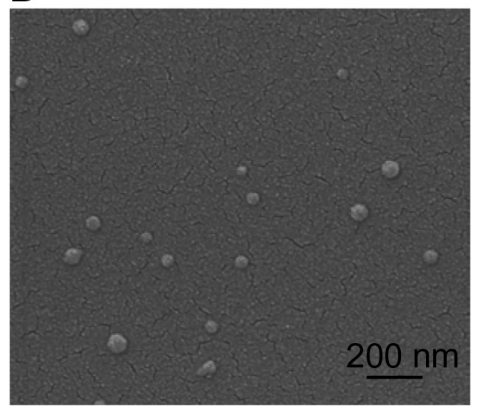

B

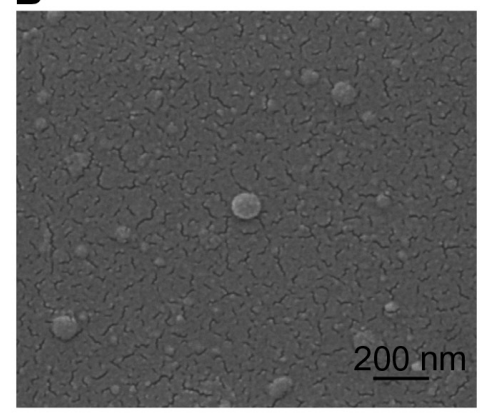

$\mathbf{E}$

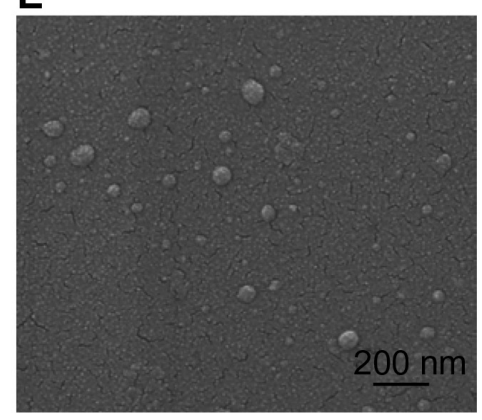

C

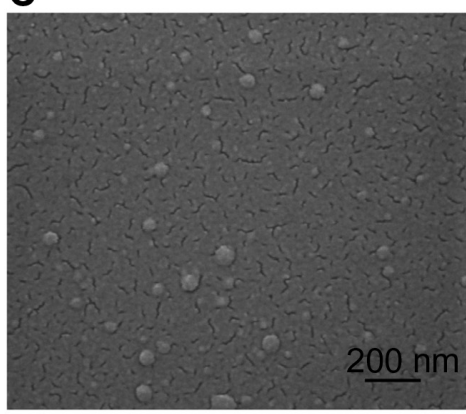

$\mathbf{F}$

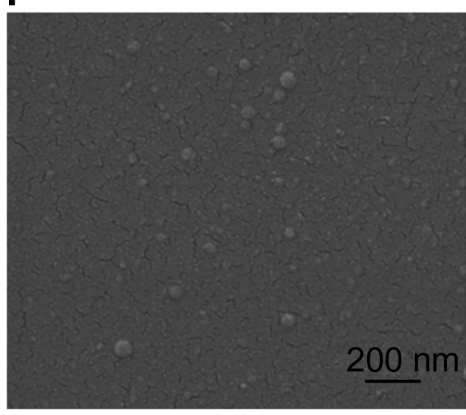

Figure I Environmental scanning electron microscopy images of spherical chitosan/dsODN nanoparticles. (A) 92-10-5 chitosan/dsODN-RecQLI nanoparticles; (B) 80-40-5 chitosan/dsODN-RecQLI nanoparticles; (C) 80-10-10 chitosan/dsODN-RecQLI nanoparticles; (D) 92-I0-5 chitosan/dsODN-ApoB nanoparticles; (E) 80-80-5 chitosan/ dsODN-ApoB nanoparticles, and (F) 80-10-10 chitosan/dsODN-ApoB nanoparticles.

Abbreviations: $\mathrm{ApoB}$, apolipoprotein $\mathrm{B}$; dsODN, double-stranded oligodeoxynucleotide.

for these specific formulations. The excess chitosan in all formulations resulted in positively charged nanoparticles as shown by $\zeta$-potential measurements (Table 2 ).

\section{Chitosan/dsODN nanoparticle stability}

Chitosan-based nanoparticles were incubated for $0.5,4$, and 20 hours in two different buffers ( $\mathrm{pH} 6.5$ and 8 ) to assess the effect of time and $\mathrm{pH}$ on nanoparticle stability (Figure 2). Nanoparticles were stable up to 20 hours at an N:P ratio above 2 in slightly acidic buffers (pH 6.5). At 4 hours following nanoparticle formation, and under slightly acidic

Table 2 Size and zeta potential values obtained by dynamic light scattering for chitosan/dsODN-RecQLI and chitosan/dsODNApoB nanoparticles

\begin{tabular}{llcll}
\hline ODN & Chitosan & $\begin{array}{l}\text { Size DLS } \\
(\mathbf{n m})\end{array}$ & $\begin{array}{l}\text { Size ESEM } \\
(\mathbf{n m})\end{array}$ & $\begin{array}{l}\text { Zeta potential } \\
(\mathbf{m V})\end{array}$ \\
\hline RecQLI & $92-10-5$ & $63 \pm 8$ & $54 \pm 6$ & $23 \pm 1$ \\
RecQLI & $80-40-5$ & $86 \pm 9$ & $97 \pm 12$ & $18 \pm 1$ \\
RecQLI & $80-10-10$ & $91 \pm 7$ & $73 \pm 9$ & $18 \pm 2$ \\
ApoB & $92-10-5$ & $45 \pm 4$ & $66 \pm 5$ & $21 \pm 2$ \\
ApoB & $80-80-5$ & $100 \pm 8$ & $75 \pm 13$ & $16 \pm 1$ \\
ApoB & $80-10-10$ & $64 \pm 6$ & $67 \pm 7$ & $19 \pm 2$ \\
\hline
\end{tabular}

Notes: Values are mean $\pm S D ; n=3$.

Abbreviations: ApoB, apolipoprotein B; dsODN, double-stranded oligodeoxynucleotides; DLS, dynamic light scattering; ESEM, environmental scanning electron microscopy; SD, standard deviation. conditions, no detectable dsODNs were observed at N:P ratios of 2 or higher (Figure 2A and $\mathrm{C}$ ). On the contrary, dsODN release was observed for the same $\mathrm{N}: \mathrm{P}$ ratios at a $\mathrm{pH}$ of 8 (Figure 2B and D). Longer exposure time - 20 hours - at a pH of 6.5 resulted in increased dsODN-ApoB release at an $\mathrm{N}: \mathrm{P}$ ratio of 2 . This pattern was not observed for the dsODNRecQL1 sequence. This may be due to sequence/structural differences between the two dsODNs. Furthermore, our results at a $\mathrm{pH}$ of 8 show a rapid partial-to-complete dsODN release after 0.5 hour at an N:P ratio of 2 (Figure 2B and D). At $\mathrm{N}: \mathrm{P}$ ratio 10 and for the same $\mathrm{pH}$ of 8 , chitosan showed a partial release of dsODNs indicating the effect of excess chitosan on preserving stability. Overall, our specific chitosan formulations assured nanoparticle stability for a minimum period of 20 hours at an N:P ratio above 2 in slightly acidic near-neutral $\mathrm{pH}$ environments.

\section{Nanoparticle protection assay}

For effective gene expression and/or inhibition, nucleic acids entrapped in the delivery vehicle must be protected from degradation by enzymes such as serum nucleases..$^{58}$ The ability of chitosan-based nanoparticles to protect siRNA mimicking dsODN sequences was assessed using a DNAse I protection assay against different chitosan formulations complexed with dsODN-RecQL1 or dsODN-ApoB. Upon incubation 


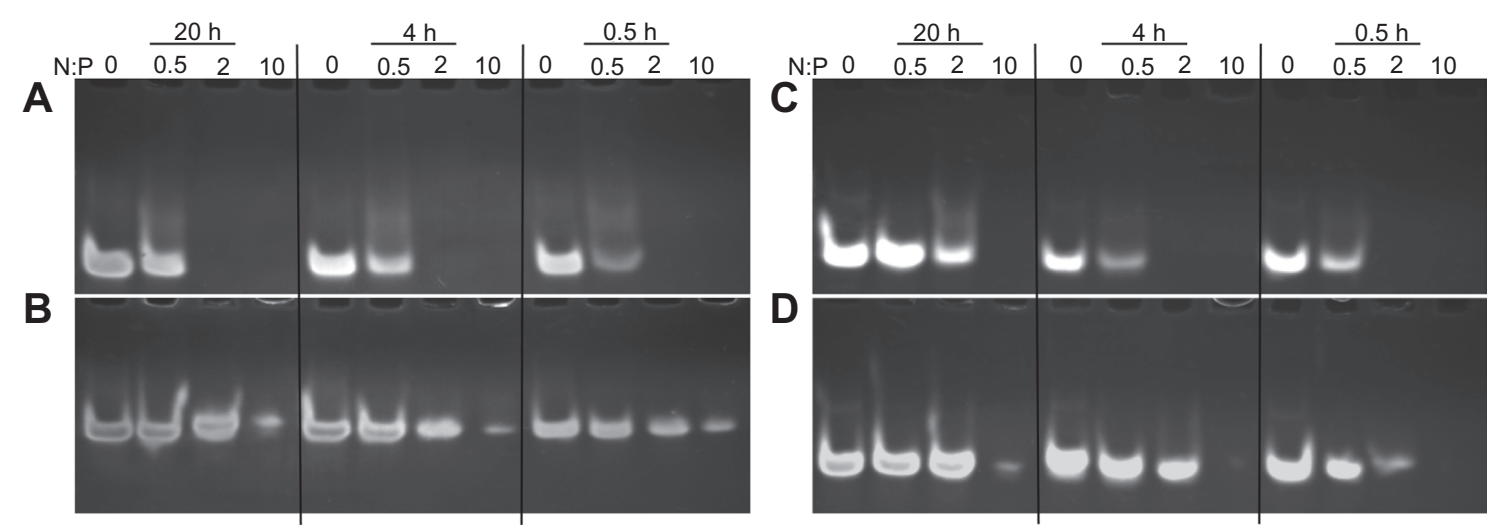

Figure 2 Chitosan nanoparticle temporal stability. Stability was assessed at $0.5,4$, and 24 hours after complex formation using polyacrylamide gel electrophoresis at a pH of 6.5 (MES IX) and pH8 (TAE IX). Chitosan 92-10 at different N:P ratios (0.5, 2, and 10) was complexed with: (A) dsODN-RecQLI at a pH of 6.5; (B) dsODN-RecQLI at a pH of 8; (C) dsODN-ApoB at a pH of 6.5, and (D) dsODN-ApoB at a pH of 8. Unstable nanoparticles release dsODNs which become visible following EtBr staining on polyacrylamide gel following ethidium bromide staining of the polyacrylamide gel.

Abbreviations: ApoB, apolipoprotein B; dsODN, double-stranded oligodeoxynucleotide; N:P, amine to phosphate.

with DNAse I, naked dsODN-RecQL1 and dsODN-ApoB (controls) were completely degraded (Figure 3A-D, lane 3). In contrast, DNAse I protection assay showed that all chitosans tested protected dsODNs from degradation at DNAse I concentrations $<2$ units DNAse I per $\mu \mathrm{g}$ dsODN (Figure 3). Chitosan formulations demonstrated an average of $\sim 80 \%$ protection of dsODNs at DNAse I concentrations of $0.5 \mathrm{U} / \mu \mathrm{g}$ (Figure 3). The ability of LMW-CS (92-10, 80-40, 80-80, and 80-10) to protect dsODNs from nuclease degradation decreased with increased concentrations of DNAse I. Our results show that protection decreased from $\sim 50 \%$ at a DNAse I concentration of $1 \mathrm{U} / \mu \mathrm{g}$ to less than $\sim 20 \%$ at $2 \mathrm{U} / \mu \mathrm{g}(92-10$ and 80-10). Moreover, our results suggest that higher $M_{\mathrm{n}}$ chitosan (80-40 and 80-80) offers a slightly better protection of dsODNs as compared to lower $M_{\mathrm{n}}$ chitosan (92-10 and 80-10)

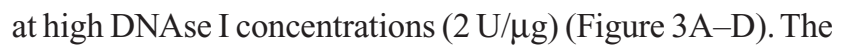
enhanced cargo protection observed with higher molecular weight chitosans is consistent with previous studies where higher binding affinities between high Mw chitosans and nucleic acids was demonstrated. ${ }^{59}$ Altogether, our results show that DNAse I protection is considerable when using intermediate to low DDA $/ M_{\mathrm{n}}$ and preserves approximately $60 \%$ of nucleic acid when using 1 unit of DNAse I per $\mu \mathrm{g}$ of dsODNs.

\section{In vitro cell uptake analysis by flow cytometry and confocal microscopy}

Nanoparticle internalization into cells can be another ratelimiting step for effective drug delivery systems. In general, efficient nanoparticle internalization depends on several factors, such as the cell type, the physicochemical surface properties of the nanoparticles, and the bio-nano interface. ${ }^{60}$
The internalization of RecQL1- and ApoB-bearing nanoparticles was assessed in two different sets of relevant cell lines using flow cytometry (FACS). For the assessment of (6FAM) dsODN-RecQL uptake, transfection and FACS analysis were performed on AsPC1, A549, and LS174T cancer cell lines whereas (6FAM) dsODN-ApoB uptake was performed on HEK293, HepG2, and Raw269.7 cell lines. Our FACS results show that cell uptake using chitosan/(6FAM) dsODN-ApoB nanoparticles achieved levels comparable to the commercially used lipoplex (DharmaFECT) (Figures 4 and 5), demonstrating the internalization efficiency of LMW-CS formulations in different cell lines. Moreover, our results indicate that different chitosan formulations show statistically significant differences in their cell uptake efficiency, with LMW-CSs 92-10-5 and 80-10-10 more easily internalized compared to the higher molecular weight $80-80-5$ and $80-40-5$, in a cell-line-dependent manner. Interestingly, the A549 and HEK293 cell lines demonstrated no statistical differences in uptake efficiency between the different chitosan formulations (Figures 4 and 5A). However, the A549 and HEK293 cell lines showed statistically significant increases in uptake when compared to the LS174T and Raw264.7 cell lines, again highlighting some important cell-type dependencies.

In general, LMW-CS (92-10-5 and 80-10-10) showed higher uptake efficiency, ranging from approximately $65 \%$ to $95 \%$ depending on the transfected cell line (Figures 4 and 5A). These results are in accordance with confocal microscopy data, where images representative of the whole population show that the vast majority of cells for each of the four cell types imaged show nanoparticle internalization (Figure 6). The lack of colocalization at 24 hours between dsODNs and chitosan indicates that complete release of the dsODN cargo 
A

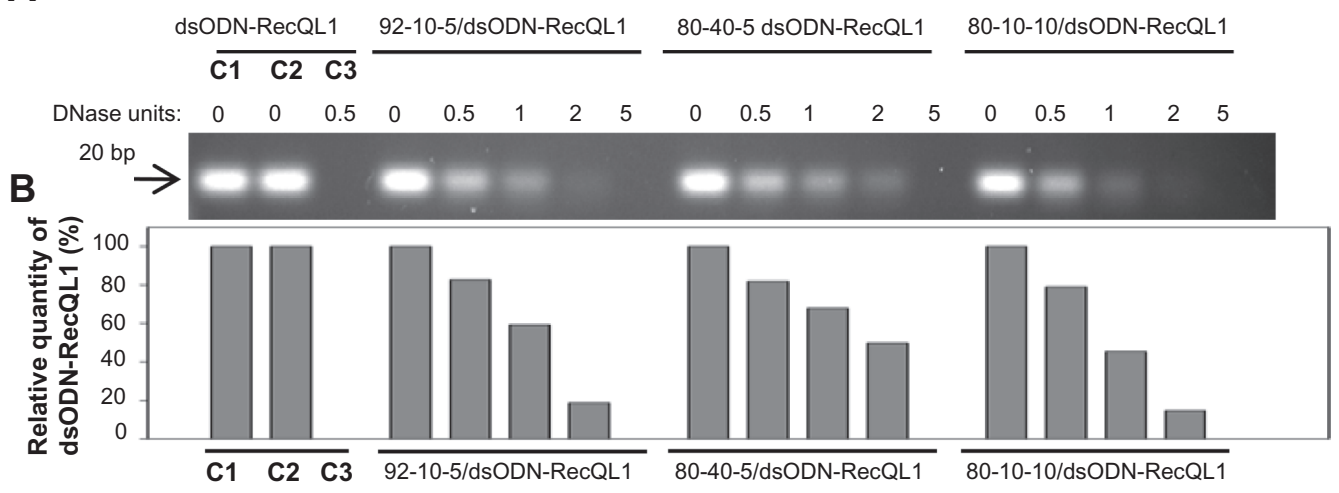

C
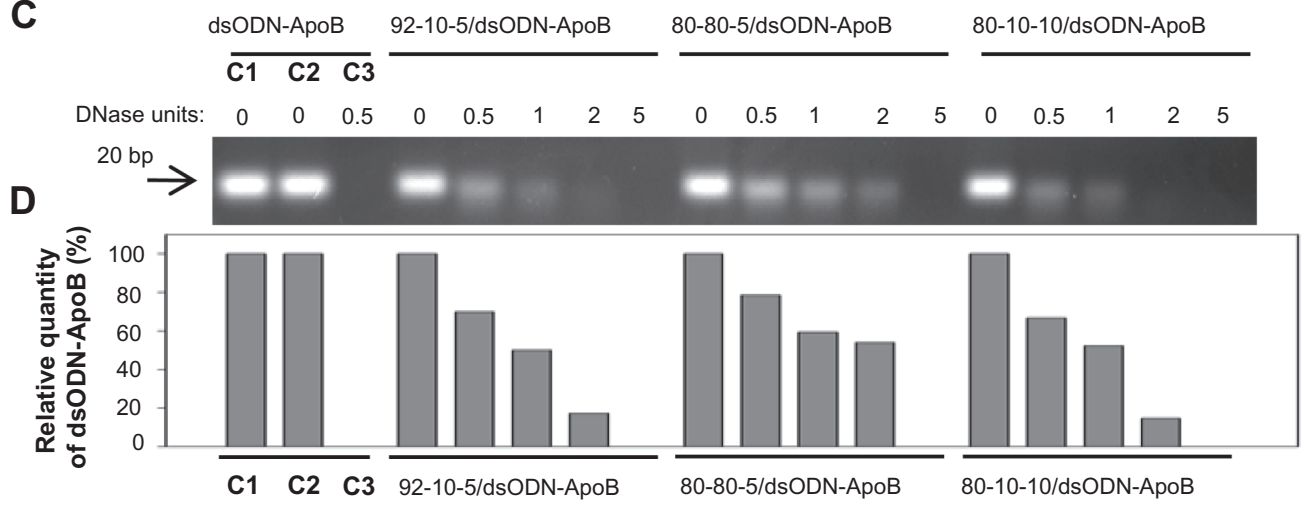

Figure 3 Nuclease protection assays of chitosan/dsODN nanocomplexes. (A) Chitosan (92-10-5, 80-40-5 or 80-I0-10) complexed with dsODN-RecQLI. (B) dsODN-RecQLI remaining after the DNAse I digestion was assessed using the signal intensity of the treated samples with the control (ie, $0 \cup \mathrm{DNAse} I=100 \%$ intensity). This comparison was made between the samples of the same chitosan formulation. (C) Chitosans (92-10-5, 80-80-5 or 80-10-10) complexed with dsODN-ApoB. (D) dsODN-ApoB remaining after the DNAse I digestion was similarly assessed as in (B).

Abbreviations: ApoB, apolipoprotein B; dsODN, double-stranded oligodeoxynucleotide.

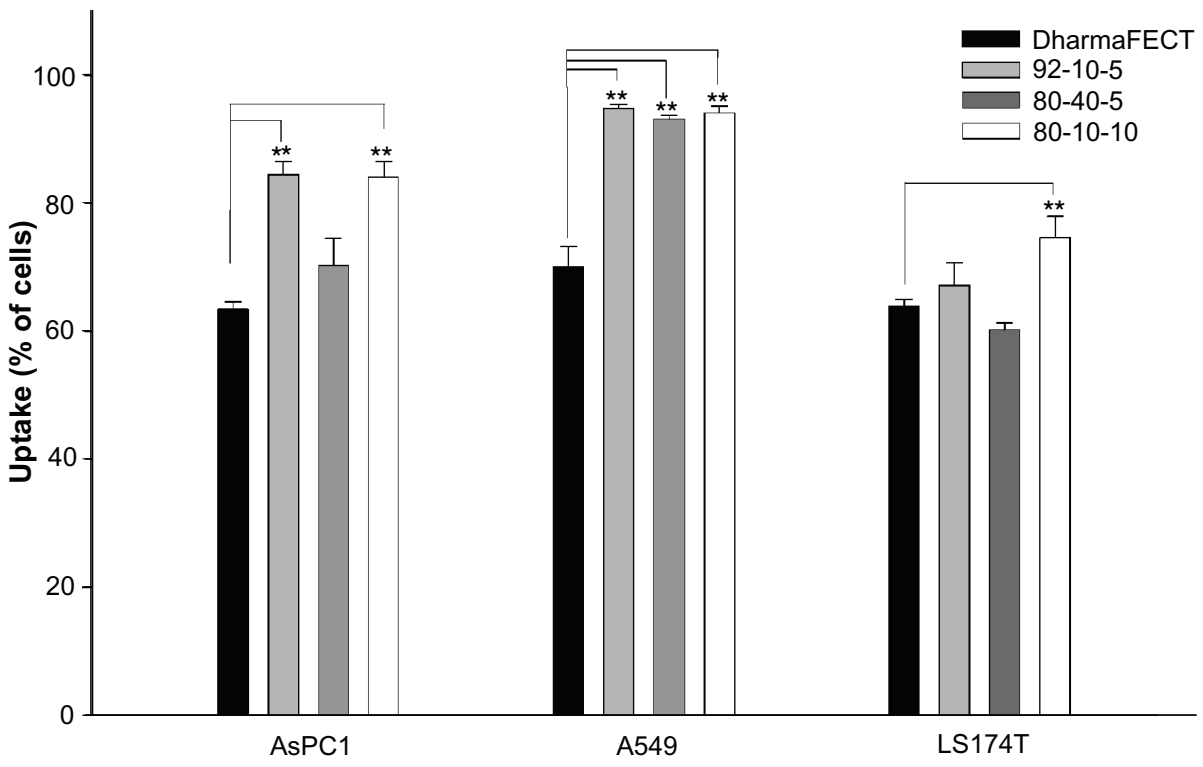

Figure 4 Cellular uptake of dsODN-RecQLI nanoparticles 24 hours post transfection in AspCI, A549, and LSI74T cancer cell lines. Chitosan formulations 92-10-5, 80-40-5, and 80-10-10 were complexed to (6FAM) 5' labeled dsODN-RecQLI and transfected at 60 pmol/well 24 hours prior to fluorescence-activated cell sorting analysis. DharmaFECT ${ }^{\text {TM }}$ was used as the positive uptake control.

Notes: Values are mean $\pm S D ; n=3 ; * * P>0.01$

Abbreviations: dsODN, double-stranded oligodeoxynucleotide; SD, standard deviation. 


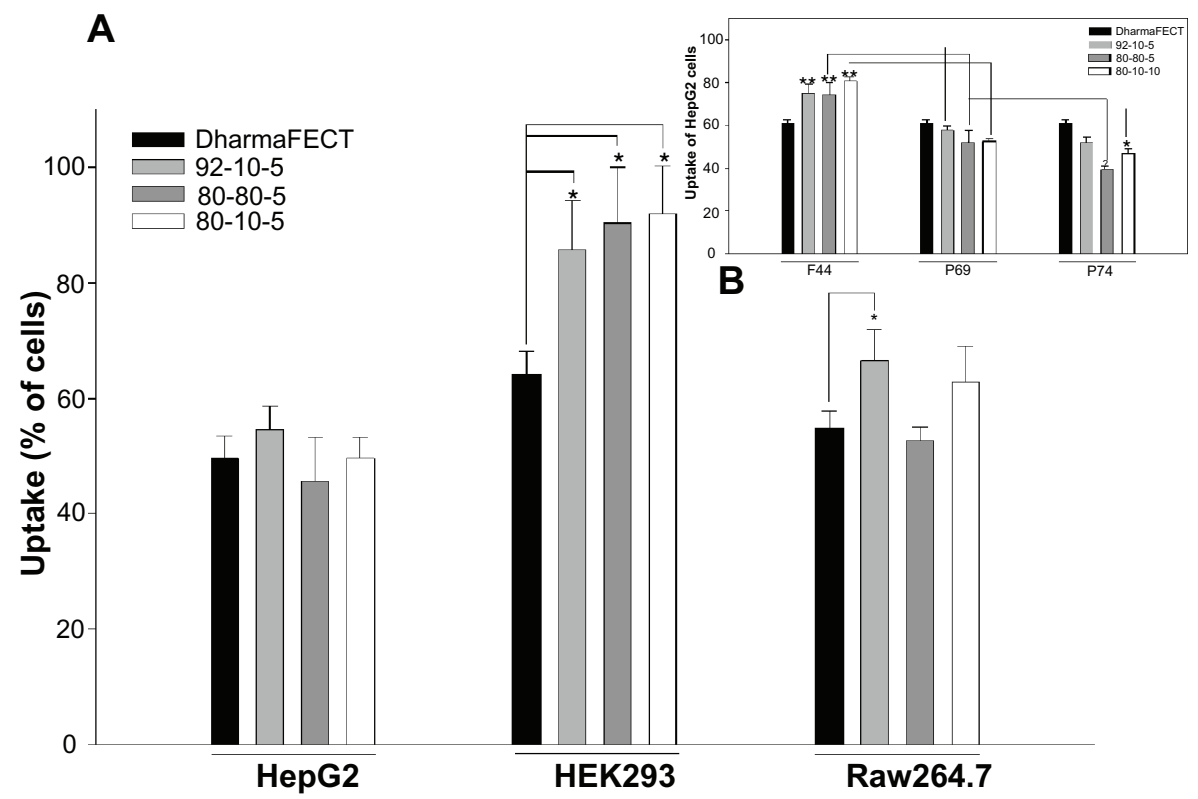

Figure 5 Cellular uptake of dsODN-ApoB nanoparticles 24 hours post transfection in HEK293, Raw269.7, and HepG2 cell lines. Chitosan formulations 92-10-5, 80-80-5, and 80-10-10 were complexed to (6FAM) 5 ' labeled dsODN-ApoB and transfected at 60 pmol/well 24 hours prior to fluorescence-activated cell sorting analysis. (A) Uptake efficiency of dsODN-ApoB in percentage (\%). (B) Uptake efficiency of dsODN-ApoB in HepG2 cells at different passage numbers. DharmaFECT TM was used as the positive uptake control.

Notes: Values are mean $\pm S D ; n=3 ; * P>0.05 ; * * P>0.01$.

Abbreviations: ApoB, apolipoprotein B; dsODN, double-stranded oligodeoxynucleotide; SD, standard deviation.

A

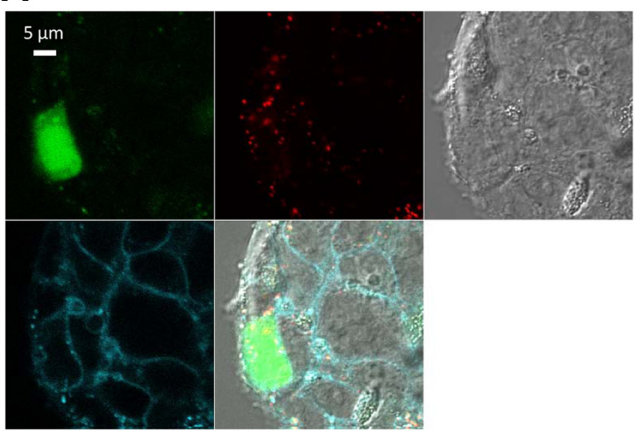

C

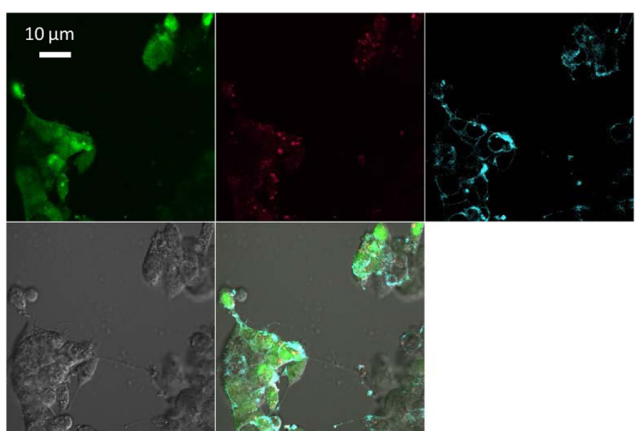

B

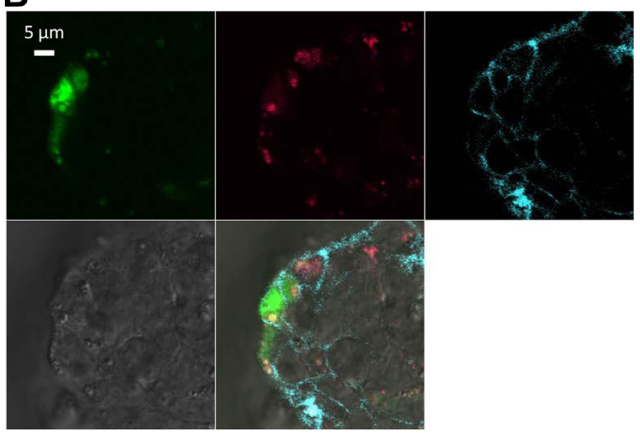

D

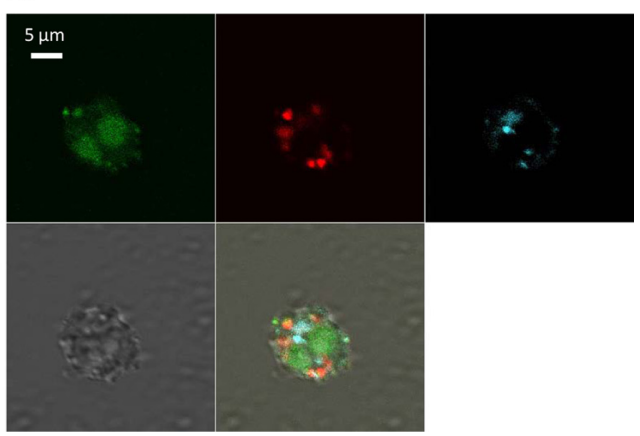

Figure 6 Confocal imaging of chitosan/dsODN nanocomplex uptake 24 hours post transfection. Chitosan $92-10$ (DDA, $M_{\mathrm{n}}$ ) was labeled with rhodamine (red) and dsODNs were $5^{\prime}$ labeled with (6FAM) (green). Chitosan 92-10 was complexed to dsODNs at an N:P ratio of 5. Cell membranes were stained prior to imaging with CellMask ${ }^{\mathrm{TM}}$ (blue) to differentiate between internalized and membrane-bound nanoparticles. Images shown represent each separate channel, with dsODNs in green, chitosan in red, membrane in blue, differential interference contrast image in grey, and the merged images shown on the bottom left quadrant. (A) LSI74T cells transfected with chitosan/dsODNRecQLI nanoparticles. (B) HepG2 cells transfected with chitosan/dsODN-ApoB nanoparticles. (C) HEK293 cells transfected with chitosan/dsODN-ApoB nanoparticles. (D) Raw 294.7 cells transfected with chitosan/dsODN-ApoB nanoparticles.

Abbreviations: ApoB, apolipoprotein B; dsODN, double-stranded oligodeoxynucleotide; $\mathrm{N}: \mathrm{P}$, amine to phosphate. 
was achieved 24 hours post transfection. Furthermore, the diffuse staining pattern of dsODNs seen in most transfected cells suggests that complexes have escaped endocytic vesicles (Figure 6), consistent with previous live cell imaging work using chitosan-plasmid DNA nanoparticles. ${ }^{40}$

\section{Specific gene silencing and cell cytotoxicity evaluation of chitosan nanoparticles in different cell lines}

Gene silencing occurs when complementarity is achieved between the siRNA seed region and target mRNA. ${ }^{1}$ Chitosan-specific formulations (92-10-5, 80-40-5, 80-10-10, and 80-80-5) were assessed for mRNA knockdown in two different cell lines relevant to cancer and atherosclerosis, targeted by RecQL1 and ApoB siRNA, respectively. qPCR analysis revealed inhibition of RecQL1 and $A p o B$ since their coding mRNAs were downregulated more than twofold (Figure 7). More specifically, in LS174T cells, chitosan 92-10-5 showed a high level of silencing $(\sim 80 \%)$ of RecQL1, similar to the current commercial gold standard liposomal formulation $(\sim 80 \%)$, used here as a positive control. Formulations $80-40-5$ and $80-10-10$ also induced significant silencing but to a lower degree than 92-10-5 and also with an increase of nonspecific mock silencing, especially for formulation 80-10-10, for reasons that remain to be elucidated. For the HepG2 cell line, only the best performing 92-10-5 was tested and induced significant silencing ( $\sim 55 \%$ versus $\sim 80 \%$ for positive control) of $A p o B$ but slightly lower than RecQL1 for LS174T. Importantly, our results showed that silencing efficiency with chitosan reached similar levels to the positive control, with a markedly reduced cytotoxicity from the delivery system as assessed using the alamarBlue assay (Figure 8).

\section{Discussion}

In this study, we evaluated the efficiency of specific low molecular weight chitosan (LMW-CS) formulations at low N:P ratios for the in vitro delivery of siRNA targeting either RecQL1 or $A p o B$ genes. RecQL1 is a DNA helicase playing a major role in homologous recombination, maintenance of genomic stability, and DNA repair at damaged replication forks. ${ }^{52,61}$ Overexpression of RecQL1 has been implicated in cancer by preventing cell apoptosis. ${ }^{6,7,62}$ As for $A p o B$, it is a major gene involved in atherosclerosis through its essential role in the formation of very low density lipoprotein which will therefore generate low density lipoproteins following triacylglycerol hydrolyzation in the circulation. ${ }^{51,63,64}$

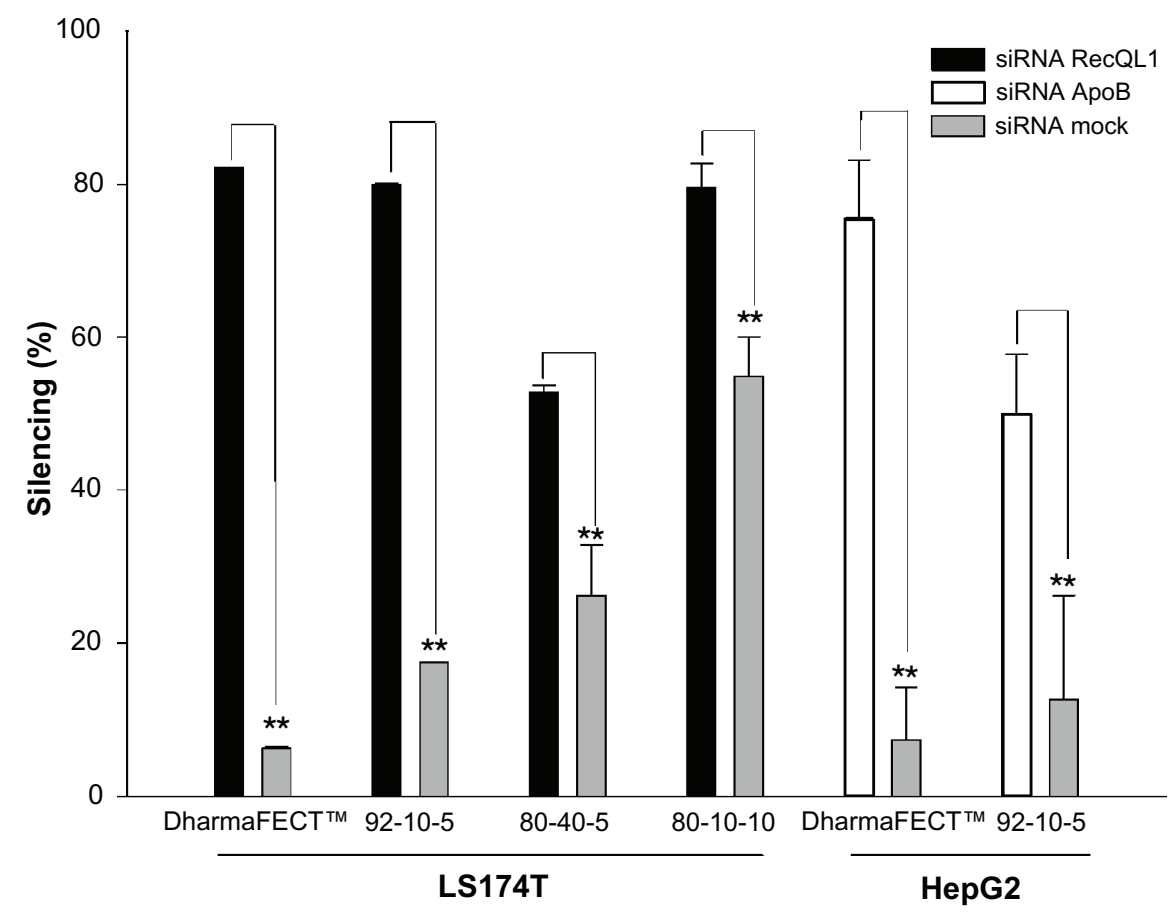

Figure 7 Real-time polymerase chain reaction analysis of the inhibition of RecQLI and ApoB gene expression in specific cell lines. LSI74T cells were transfected with chitosan (92-10-5, 80-40-5, and 80-10-10)/siRNA-RecQLI nanoparticles, whereas HepG2 cells were transfected with chitosan (92-I0-5)/siRNA-ApoB nanoparticles. The inhibition percentage was obtained by comparing the transfected and nontransfected cells, using the $\triangle \triangle C T$ method.

Notes: Values are mean $\pm S D ; n=3 ; * * p>0.01$.

Abbreviations: ApoB, apolipoprotein B; siRNA, small interfering RNA; SD, standard deviation. 


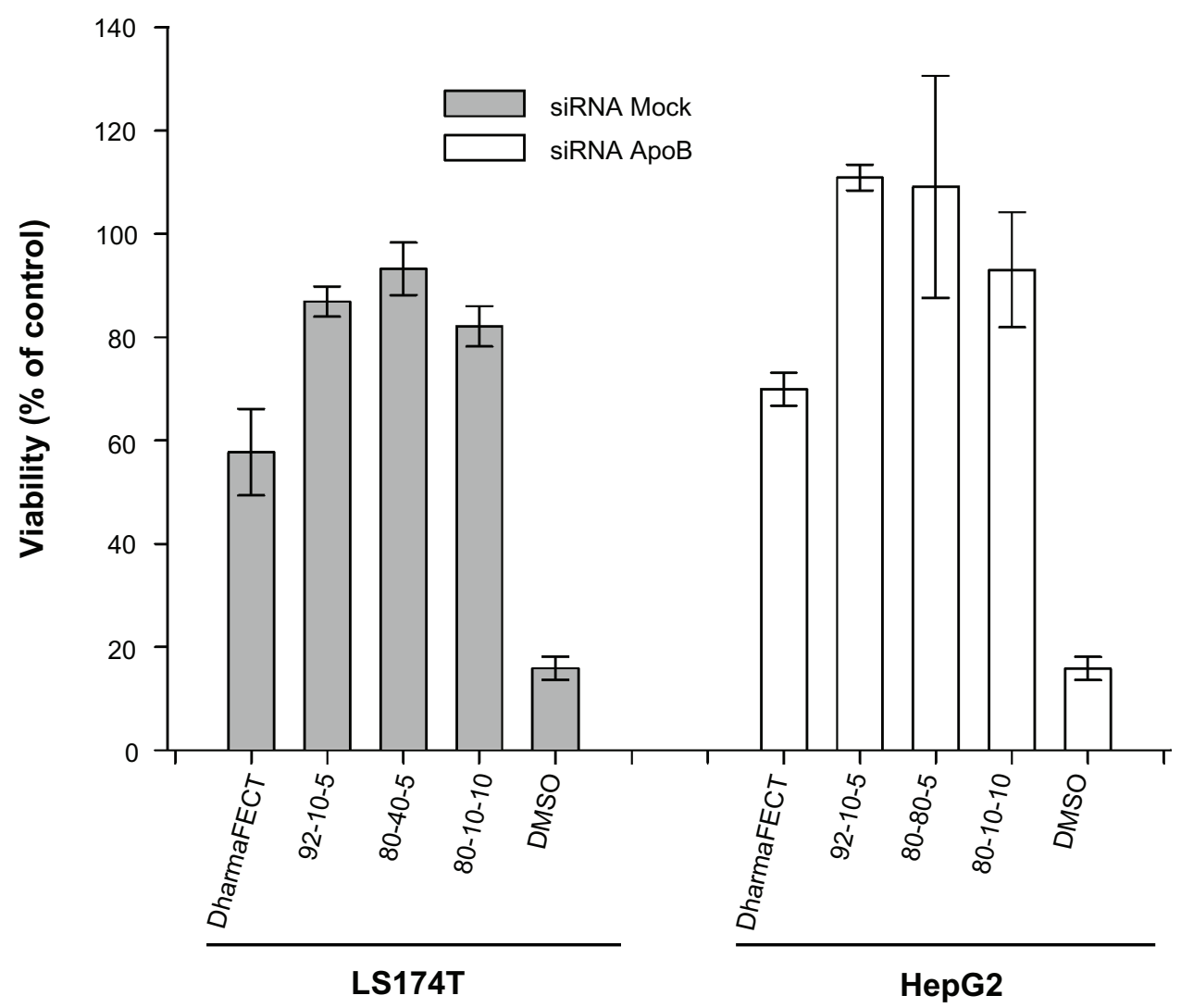

Figure 8 Cell viability assessment using the alamarBlue ${ }^{\circledR}$ assay 24 hours post transfection with different chitosan/siRNA formulations. To alleviate the apoptotic effect of RecQLI gene silencing for a proper assessment of chitosan-siRNA toxicity, mock siRNA was used for transfection in the LSI74T cell line. The HepG2 cell line was transfected with ApoB siRNA. DharmaFECT TM was used for comparison purposes whereas dimethyl sulfoxide was used as a positive control of toxicity.

Notes: Values are presented as mean $\pm S D ; n=3$.

Abbreviations: $A p o B$, apolipoprotein $B$; siRNA, small interfering RNA.

Nanoparticle size is one parameter affecting uptake and intracellular trafficking, both considered as potential ratelimiting steps for effective gene therapy. ${ }^{41,42}$ For instance, nano-sized particles have been shown to be internalized more efficiently than micro-sized particles. ${ }^{65-67}$ In this study, LMWCS-based nanoparticles ranged in size from $41-110 \mathrm{~nm}$, a size range promoting uptake, prolonged blood circulation, higher tissue penetration, and a relatively free passage from the mononuclear phagocyte system. ${ }^{48,68-70}$ Therefore, our results show that these specific LMW-CS nanoparticles at low N:P ratios meet performance criteria (Table 3 ) and are potentially relevant for in vivo administration. The different chitosan parameters - DDA, $M_{\mathrm{n}}$, and N:P ratios - used in this study did not significantly affect nanoparticle size, with higher molecular weight chitosan promoting a slightly increased size (Table 1). Our results are in contrast to previously published reports where the authors found increased nanoparticle size for lower molecular weight chitosan. ${ }^{43}$ This discrepancy may be due to differences in experimental conditions and to the high N:P ratio used in Liu et al and Howard et al reports ${ }^{8,43}$ versus low N:P ratios reported in our study. ESEM analysis revealed that these small nanoparticles were of spherical shape consistent with previous findings for pDNA,${ }^{37}$ siRNA, ${ }^{8}$ and dsODNs. ${ }^{71}$ The effect of nanoparticle shape on internalization efficiency showed spherical particles of similar size being internalized $500 \%$ more efficiently than rod-shaped particles. ${ }^{72-74}$ This is mainly explained by increased membrane-wrapping time required for elongated particles and greater thermodynamic forces required for their engulfment. ${ }^{60,74}$ It was previously demonstrated that the morphology of chitosan-pDNA nanoparticles is strongly dependent upon their charge ratios, and the variation of the latter resulted in nanoparticles with different topological conformations including spherical, ${ }^{75}$ toroidal, ${ }^{76,77}$ and globular morphologies. ${ }^{76,78}$ Chitosan-based nanoparticle shape may also seem to be affected by the type of nucleic acid - pDNA or siRNA/dsODN - used for complexation and the process of nanoparticle formation; ie, ionic gelation. The fact that these LMW-CS nanoparticles demonstrated a reproducible pattern of spherical particles at low N:P ratios may be indicative of higher internalization efficiency than nanoparticles of different topological conformations. 
Table 3 Safety and performance criteria for the development of effective nonviral gene delivery systems

\begin{tabular}{|c|c|}
\hline Categories & Performance criteria** \\
\hline $\begin{array}{l}\text { Physical and } \\
\text { chemical properties }\end{array}$ & $\begin{array}{l}\text { - Nanoparticle formation/assembly at a nucleic } \\
\text { acid scale of } 10 \mathrm{mg} \text {, from the perspective of } \\
\text { size, shape, aggregation, and charge, as well as } \\
\text { from an efficacy standpoint (such as toxicity } \\
\text { and transfection efficacy), should be } \\
\text { similar/reproducible each time } \\
\text { nanoparticles are formed at this and lower } \\
\text { concentrations } \\
\text { - Assemblies less than } 300 \mathrm{~nm}, \mathrm{PDI}(<0.3) \text { and } \\
\text { no less than } 80 \% \text { incorporation efficiency } \\
\text { - No aggregation in } 50 \% \text { mouse/human serum } \\
\text { - Chemical stability of the assembly for }>30 \text { days } \\
\text { - Preferably amenable to freeze-drying } \\
\text { without any loss of its performance criteria }\end{array}$ \\
\hline $\begin{array}{l}\text { Activity in cell } \\
\text { based assays* }\end{array}$ & $\begin{array}{l}\text { - }>50 \% \text { reducation in target mRNA by target } \\
\text { specific siRNA at concentrations }<100 \mathrm{~nm} \\
\text { in } 10 \% \text { serum containing media } \\
-<10 \% \text { reduction in target mRNA by control } \\
\text { siRNA at concentrations }<100 \mathrm{~nm} \text { in } 10 \% \\
\text { serum containing media } \\
\text { - }>5 \text {-fold window between target gene silencing } \\
\text { IC50 and IC50 for reduction in viability } \\
\text { - Activity in at least relevant } 3 \text { cell lines to the } \\
\text { delivery system under evaluation }\end{array}$ \\
\hline $\begin{array}{l}\text { Performance and } \\
\text { safety in animal } \\
\text { models }\end{array}$ & $\begin{array}{l}\text { - }>50 \% \text { reduction in target mRNA levels by } \\
\text { target siRNA and }<10 \% \text { reduction in target } \\
\text { mRNA levels in target tissue at I mg/kg dose } \\
\text { by control siRNA by } 24-48 \mathrm{hr} \\
\text { - Demonstration of RNAi-mediated target } \\
\text { mRNA cleavage by } 5 \text { '-RACE } \\
\text { - }<10 \text {-fold cytokine induction (TNF } \alpha \text {, IFN } \beta \text {, } \\
\text { IL6) and }<10 \text {-fold increase in ALT and AST } \\
\text { at } 3 \mathrm{mg} / \mathrm{kg} \text { siRNA dose } \\
\text { - No effect on body weight and normal blood } \\
\text { clinical chemistry and hematology data } \\
\text { - Lack of immunogenicity } \\
\text { - Lack of auto-antibodies and anti-DNA } \\
\text { antibodies } \\
\text { - Lack of systemic toxicity } \\
\text { - No effect on body weight and normal blood } \\
\text { clinical chemistry and hematology data }\end{array}$ \\
\hline
\end{tabular}

Notes: *If the delivery platform incorporates a targeting moiety evidence should be provided for targeting by (a) using cell lines with differential expression of targeted receptor and (b) using assemblies with "active" and "inactive or mutant" targeting moieties; **performance criteria described here are for both siRNA and plasmid DNA delivery systems. The criteria in this table has been adapted from information in US FDA $^{84,85}$ and US Pharmacopeia. ${ }^{86}$

Abbreviations: PDI, polydispersity index; mRNA, messenger RNA; siRNA, small interfering RNA; IC50, half maximal inhibitory concentration; RACE, rapid amplification of cDNA ends; ALT, alanine transaminase; AST, aspartate transaminase.

Nanoparticle stability and nucleic acid protection are important parameters for efficient nucleic acid delivery. Our results of nuclease protection indicate that all LMW-CS formulations tested were able to protect dsODNs at supraphysiological concentrations of nucleases. Nuclease protection is of great importance for nucleic acid delivery systems through maintenance of cargo bioavailability and improved pharmacokinetic profile, thereby increasing the therapeutic potential of these nanoparticles. Increasing chitosan molecular weight resulted in an enhanced cargo protection (Figure 3) in agreement with previous findings. ${ }^{17,38,42,43,46}$ Nevertheless, enhancing the ability of nanoparticles to protect their siRNA from degradation may render their intracellular disassembly more difficult, as demonstrated with high molecular weight chitosan-pDNA nanoparticles. ${ }^{40}$ Further characterization of nanoparticle stability by gel retardation assays show that LMW-CS used at low N:P ratios can effectively complex and compact dsODNs into stable particles. We found LMW-CS nanoparticles at N:P ratios above 2 to be stable in slightly acidic buffers for at least 20 hours. These interesting findings are in contrast with most previous studies using chitosansiRNA nanoparticles, where high $M_{\mathrm{n}}$ and high N:P ratios are usually required to achieve particle stability. ${ }^{8,17,42,43,79}$ This discrepancy can be explained by the lower $\mathrm{pH}(\mathrm{pH} 6.5$ ) of the electrophoresis buffer in our study compared to the commonly used TAE buffer at a $\mathrm{pH}$ of 8 for chitosan-based nanoparticle characterization, ${ }^{8,17,42,43,80}$ a difference that was clearly highlighted by our gel retardation assay performed at both pHs (Figure 2). The use of a lower $\mathrm{pH}$ in the electrophoresis buffer results in higher degrees of chitosan ionization which translates to stronger electrostatic attraction to the polyanionic nucleic acid and hence more stable nanoparticles. This simple modification of the $\mathrm{pH}$ permits lower $\mathrm{N}: \mathrm{P}$ ratios than those observed previously $y^{8,17,42,43,80}$ to achieve nanoparticle stability. A direct consequence of this modification translates into reduced dosing, aggregation, and other undesirable nonspecific effects of large quantities of soluble chitosan for in vivo delivery where nanoparticles are to be injected at physiological $\mathrm{pH}$ values close to the chitosan $\mathrm{p} K_{\mathrm{a}}$ of 6.5 .

In general, efficient nanoparticle internalization depends on factors such as cell type, physicochemical surface properties of the nanoparticles, and the bio-nano interface. ${ }^{60}$ In this report, we demonstrated that LMW-CS nanoparticles were efficiently internalized in multiple cell lines. The uptake efficiency as measured by flow cytometry ranged from $50 \%$ (Raw269.7) to 95\% (A549 and HEK293), depending on the cell line. Statistical analysis of uptake efficiency intercell lines showed meaningful differences when comparing the A549 and HEK293 (high uptake) to the LS174T and Raw269.7 (medium uptake), indicating a cell-line dependency of chitosan uptake. The cell-line dependency of chitosan nanoparticles uptake was previously suggested to be associated with different endocytic pathways. ${ }^{81,82}$ Flow cytometry data 
showed LMW-CS nanoparticles to be efficiently internalized to levels similar or higher than commercially available liposomal systems such as DharmaFECT.

Finally, the transfection efficiency of LMW-CS nanoparticles as measured by gene-silencing efficacy was evaluated in two different cell lines: RecQL1 in LS174T cells and ApoB in HepG 2 cells. The ability of these chitosan formulations to efficiently silence gene expression reached more than a twofold specific mRNA knockdown; with chitosan 92-10-5 being the most efficient and specific in the LS174T cell line. Other low molecular weight formulations also achieved good levels of gene silencing in the LS174T cell line. Interestingly, chitosan 80-10-10 achieved a high level of silencing with a concomitant increase in silencing when delivering mock siRNA. This intriguing observation is currently under investigation in our laboratory. The chitosan formulation 92-10-5 complexed to ApoB siRNA showed lower target mRNA knockdown in HepG2 when compared to the LS174T cell lines targeted with the RecQL1 siRNA. The silencing efficiency correlated well with uptake efficiency as observed by flow cytometry where chitosan 92-10-5 showed both high uptake and high silencing efficiencies. Despite structural differences between pDNA and siRNA, ${ }^{46}$ the chitosan formulation $92-10-5$ has shown the highest transfection efficiencies for both siRNA and pDNA to date. ${ }^{37-41}$ Taken together, our results show that LWM-CS nanoparticles at low N:P ratios can achieve efficient uptake and gene silencing in vitro, serving as a proof of concept for their use as efficient siRNA delivery vectors in cancer and atherosclerotic animal models. Although in vitro and in vivo performance criteria differ, no consensus on such performances has been established. For in vivo performance, safety remains the major issue, with guidance available from the US Food and Drug Administration for the development of gene and cell therapy products. ${ }^{83}$ Therefore, the development of nonviral drug delivery systems for in vivo use should take into account physicochemical criteria, cell-based criteria, and, most importantly, in vivo performance and safety criteria (Table 3). The low molecular weight, low N:P system presented here meets many of these criteria and has already been demonstrated as efficient in vivo for plasmid DNA delivery. ${ }^{37,41}$ Thus a complete characterization of the safety and in vivo performance of our LMW-CS system delivering RecQL1 and ApoB targeting siRNA is currently under investigation in animal models of cancer and atherosclerosis.

\section{Acknowledgments}

This work was supported by the National Science and Engineering Research Council (NSERC) and by the Groupe de Recherche en Sciences et Technologies Biomédicales of the Fonds de la Recherche en Santé Quebec. We are grateful to Dr Monica Nelea for the ESEM analyses.

\section{Disclosure}

The authors declare no conflicts of interest in this work.

\section{References}

1. de Fougerolles A, Vornlocher HP, Maraganore J, Lieberman J. Interfering with disease: a progress report on siRNA-based therapeutics. Nat Rev Drug Discov. 2007;6(6):443-453.

2. Fire A, Xu S, Montgomery MK, Kostas SA, Driver SE, Mello CC. Potent and specific genetic interference by double-stranded RNA in Caenorhabditis elegans. Nature. 1998;391(6669):806-811.

3. Alameh M, Jean M, DeJesus D, Buschmann MD, Merzouki A. Chitosanase-based method for RNA isolation from cells transfected with chitosan/siRNA nanocomplexes for real-time RT-PCR in gene silencing. Int J Nanomedicine. 2010;5:473.

4. Bantounas I, Phylactou LA, Uney JB. RNA interference and the use of small interfering RNA to study gene function in mammalian systems. J Mol Endocrinol. 2004;33(3):545-557.

5. Castanotto D, Rossi JJ. The promises and pitfalls of RNA-interferencebased therapeutics. Nature. 2009;457(7228):426-433.

6. Futami K, Kumagai E, Makino H, et al. Induction of mitotic cell death in cancer cells by small interference RNA suppressing the expression of RecQL1 helicase. Cancer Sci. 2008;99(1):71-80.

7. Futami K, Kumagai E, Makino H, et al. Anticancer activity of RecQL1 helicase siRNA in mouse xenograft models. Cancer Sci. 2008; 99(6):1227-1236.

8. Howard KA, Rahbek UL, Liu X, et al. RNA interference in vitro and in vivo using a novel chitosan/siRNA nanoparticle system. Mol Ther. 2006;14(4):476-484

9. Soutschek J, Akinc A, Bramlage B, et al. Therapeutic silencing of an endogenous gene by systemic administration of modified siRNAs. Nature. 2004;432(7014):173-178.

10. Zimmermann TS, Lee AC, Akinc A, et al. RNAi-mediated gene silencing in non-human primates. Nature. 2006;441(7089):111-114.

11. Elbashir SM, Harborth J, Lendeckel W, Yalcin A, Weber K, Tuschl T. Duplexes of 21-nucleotide RNAs mediate RNA interference in cultured mammalian cells. Nature. 2001;411(6836):494-498.

12. Whelan J. First clinical data on RNAi. Drug Discov Today. 2005;10(15): 1014-1015.

13. Corey DR. RNA learns from antisense. Nat Chem Biol. 2007;3(1): $8-11$.

14. Corey DR. Chemical modification: the key to clinical application of RNA interference? J Clin Invest. 2007;117(12):3615-3622.

15. Stein CA. Phosphorothioate antisense oligodeoxynucleotides: questions of specificity. Trends Biotechnol. 1996;14(5):147-149.

16. Urban-Klein B, Werth S, Abuharbeid S, Czubayko F, Aigner A. RNAi-mediated gene-targeting throught systemic application of polyethylenimine (PEI)-complexed siRNA in vivo. Gene Ther. 2004; 12(5):461-466.

17. Katas H, Alpar HO. Development and characterisation of chitosan nanoparticles for siRNA delivery. J Control Release. 2006;115(2): 216-225.

18. Elmen J, Thonberg H, Ljungberg K, et al. Locked nucleic acid (LNA) mediated improvements in siRNA stability and functionality. Nucleic Acids Res. 2005;33(1):439-447.

19. Judge AD, Bola G, Lee AC, MacLachlan I. Design of noninflammatory synthetic siRNA mediating potent gene silencing in vivo. Mol Ther. 2006;13(3):494-505.

20. Whitehead KA, Langer R, Anderson DG. Knocking down barriers: advances in siRNA delivery. Nat Rev Drug Discov. 2009;8(2): 129-138. 
21. Bramsen JB, Laursen MB, Nielsen AF, et al. A large-scale chemical modification screen identifies design rules to generate siRNAs with high activity, high stability and low toxicity. Nucleic Acids Res. 2009;37(9):2867-2881.

22. Layzer JM, McCaffrey AP, Tanner AK, Huang Z, Kay MA, Sullenger BA. In vivo activity of nuclease-resistant siRNAs. RNA. 2004;10(5):766-771.

23. Weyermann J, Lochmann D, Georgens C, Zimmer A. Albuminprotamine-oligonucleotide-nanoparticles as a new antisense delivery system. Part 2: cellular uptake and effect. Eur J Pharm Biopharm. 2005; 59(3):431-438.

24. Amarzguioui M, Holen T, Babaie E, Prydz H. Tolerance for mutations and chemical modifications in a siRNA. Nucleic Acids Res. 2003; 31(2):589-595.

25. Parrish S, Fleenor J, Xu S, Mello C, Fire A. Functional anatomy of a dsRNA trigger: differential requirement for the two trigger strands in RNA interference. Mol Cell. 2000;6(5):1077-1087.

26. Braasch DA, Jensen S, Liu Y, et al. RNA interference in mammalian cells by chemically-modified RNA. Biochemistry. 2003; 42(26):7967-7975.

27. Harborth J, Elbashir SM, Vandenburgh K, et al. Sequence, chemical, and structural variation of small interfering RNAs and short hairpin RNAs and the effect on mammalian gene silencing. Antisense Nucleic Acid Drug Dev. 2003;13(2):83-105.

28. Reasor MJ, Kacew S. Drug-induced phospholipidosis: are there functional consequences? Exp Biol Med (Maywood). 2001;226(9):825-830.

29. Tousignant JD, Gates AL, Ingram LA, et al. Comprehensive analysis of the acute toxicities induced by systemic administration of cationic lipid:plasmid DNA complexes in mice. Hum Gene Ther. 2000; 11(18):2493-2513.

30. Ishida T, Ichihara M, Wang X, et al. Injection of PEGylated liposomes in rats elicits PEG-specific IgM, which is responsible for rapid elimination of a second dose of PEGylated liposomes. J Control Release. 2006;112(1):15-25.

31. Judge A, McClintock K, Phelps JR, MacLachlan I. Hypersensitivity and loss of disease site targeting caused by antibody responses to PEGylated liposomes. Mol Ther. 2006;13(2):328-337. Epub November 7, 2005.

32. Semple SC, Harasym TO, Clow KA, Ansell SM, Klimuk SK, Hope MJ. Immunogenicity and rapid blood clearance of liposomes containing polyethylene glycol-lipid conjugates and nucleic acid. J Pharmacol Exp Ther. 2005;312(3):1020-1026. Epub November 3, 2004.

33. Boeckle S, von Gersdorff K, van der Piepen S, Culmsee C, Wagner E, Ogris M. Purification of polyethylenimine polyplexes highlights the role of free polycations in gene transfer. J Gene Med. 2004;6(10):1102-1111.

34. Moghimi SM, Symonds P, Murray JC, Hunter AC, Debska G, SzewczykA. A two-stage poly(ethylenimine)-mediated cytotoxicity: implications for gene transfer/therapy. Mol Ther. 2005;11(6):990-995.

35. Hunter AC, Moghimi SM. Cationic carriers of genetic material and cell death: a mitochondrial tale. Biochim Biophys Acta. 2010; 1797(6-7):1203-1209.

36. Al-Dosari MS, Gao X. Nonviral gene delivery: principle, limitations, and recent progress. AAPS J. 2009;(4):671-681. Epub October 16, 2009.

37. Jean M, Smaoui F, Lavertu M, et al. Chitosan-plasmid nanoparticle formulations for IM and SC delivery of recombinant FGF-2 and PDGF-BB or generation of antibodies. Gene Ther. 2009;16(9): 1097-1110.

38. Lavertu M, Méthot S, Tran-Khanh N, Buschmann MD. High efficiency gene transfer using chitosan/DNA nanoparticles with specific combinations of molecular weight and degree of deacetylation. Biomaterials. 2006;27(27):4815-4824

39. Nimesh S, Thibault MM, Lavertu M, Buschmann MD. Enhanced gene delivery mediated by low molecular weight chitosan/DNA complexes: effect of pH and serum. Mol Biotechnol. 2010;46(2):182-196.

40. Thibault M, Nimesh S, Lavertu M, Buschmann MD. Intracellular trafficking and decondensation kinetics of chitosan-pDNA polyplexes. $\mathrm{Mol}$ Ther. 2010;18(10):1787-1795.
41. Jean M, Alameh M, Buschmann MD, Merzouki A. Effective and safe gene-based delivery of GLP-1 using chitosan/plasmid-DNA therapeutic nanocomplexes in an animal model of Type 2 Diabetes. Gene Ther. 2011;18(8):807-816.

42. Howard KA, Kjems J. Polycation-based nanoparticle delivery for improved RNA interference therapeutics. Expert Opin Biol Ther. 2007;7(12):1811-1822.

43. Liu X, Howard KA, Dong M, et al. The influence of polymeric properties on chitosan/siRNA nanoparticle formulation and gene silencing. Biomaterials. 2007;28(6):1280-1288.

44. de Campos AM, Diebold Y, Carvalho EL, Sanchez A, Alonso MJ. Chitosan nanoparticles as new ocular drug delivery systems: in vitro stability, in vivo fate, and cellular toxicity. Pharm Res. 2004;21(5): 803-810.

45. Onishi H, Machida Y. Biodegradation and distribution of water-soluble chitosan in mice. Biomaterials. 1999;20(2):175-182.

46. Mao S, Sun W, Kissel T. Chitosan-based formulations for delivery of DNA and siRNA. Adv Drug Deliv Rev. 2010;62(1):12-27.

47. Richardson SC, Kolbe HV, Duncan R. Potential of low molecular mass chitosan as a DNA delivery system: biocompatibility, body distribution and ability to complex and protect DNA. Int J Pharm. 1999; 178(2):231-243.

48. Huang M, Khor E, Lim LY. Uptake and cytotoxicity of chitosan molecules and nanoparticles: effects of molecular weight and degree of deacetylation. Pharm Res. 2004;21(2):344-353.

49. Wiegand C, Winter D, Hipler UC. Molecular-weight-dependent toxic effects of chitosans on the human keratinocyte cell line HaCaT. Skin Pharmacol Physiol. 2010;23(3):164-170.

50. Ma PL, Buschmann MD, Winnik FM. One-step analysis of DNA/ chitosan complexes by field-flow fractionation reveals particle size and free chitosan content. Biomacromolecules. 2010;11(3):549-554.

51. Olofsson SO, Boren J. Apolipoprotein B: a clinically important apolipoprotein which assembles atherogenic lipoproteins and promotes the development of atherosclerosis. J Intern Med 2005;258(5):395-410.

52. Sharma S, Doherty KM, Brosh RM Jr. Mechanisms of RecQ helicases in pathways of DNA metabolism and maintenance of genomic stability. Biochem J. 2006;398(3):319-337.

53. Scaringe SA, Wincott FE, Caruthers MH. Novel RNA synthesis method using 5'-silyl-2'-orthoester protecting groups. J Am Chem Soc. 1998;120:11820-11821.

54. Nguyen S, Hisiger S, Jolicoeur M, Winnik FM, Buschmann MD. Fractionation and characterization of chitosan by analytical SEC and ${ }^{1} \mathrm{H}-\mathrm{NMR}$ after semi-preparative SEC. Carbohydr Polym. 2009;75:636-646.

55. Nguyen S, Winnik FM, Buschmann MD. Improved reproducibility in the determination of the molecular weight of chitosan by analytical size exclusion chromatography. Carbohydr Polym. 2009;75:528-533.

56. Lavertu M, Xia Z, Serreqi AN, et al. A validated ${ }^{1} \mathrm{H}-\mathrm{NMR}$ method for the determination of the degree of deacetylation of chitosan. J Pharm Biomed Anal. 2003;32(6):1149-1158.

57. Skrypina NA, Timofeeva AV, Khaspekov GL, Savochkina LP, Beabealashvilli R. Total RNA suitable for molecular biology analysis. J Biotechnol. 2003;105(1-2):1-9.

58. Quong D, Neufeld RJ. DNA protection from extracapsular nucleases, within chitosan- or poly-L-lysine-coated alginate beads. Biotechnol Bioeng. 1998;60(1):124-134.

59. Ma PL, Lavertu M, Winnik FM, Buschmann MD. New insights into chitosan-DNA interactions using isothermal titration microcalorimetry. Biomacromolecules. 2009;10(6):1490-1499.

60. Nel AE, Madler L, Velegol D, et al. Understanding biophysicochemical interactions at the nano-bio interface. Nat Mater. 2009;8(7):543-557.

61. Wu L, Hickson ID. DNA helicases required for homologous recombination and repair of damaged replication forks. Annu Rev Genet. 2006;40:279-306.

62. Kawabe T, Tsuyama N, Kitao S, et al. Differential regulation of human RecQ family helicases in cell transformation and cell cycle. Oncogene. 2000;19(41):4764-4772. 
63. Schaefer JR, Scharnagl H, Baumstark MW, et al. Homozygous familial defective apolipoprotein B-100. Enhanced removal of apolipoprotein E-containing VLDLs and decreased production of LDLs. Arterioscler Thromb Vasc Biol. 1997;17(2):348-353.

64. Itabe H. Oxidative modification of LDL: its pathological role in atherosclerosis. Clin Rev Allergy Immunol. 2009;37(1):4-11.

65. Gref R, Domb A, Quellec P, et al. The controlled intravenous delivery of drugs using PEG-coated sterically stabilized nanospheres. Adv Drug Deliv Rev. 1995;16:215-233.

66. Bivas-Benita M, Romeijn S, Junginger HE, Borchard G. PLGA-PEI nanoparticles for gene delivery to pulmonary epithelium. Eur J Pharm Biopharm. 2004;58(1):1-6.

67. Panyam J, Labhasetwar V. Biodegradable nanoparticles for drug and gene delivery to cells and tissue. Adv Drug Deliv Rev. 2003; 55(3):329-347.

68. Guy J, Drabek D, Antoniou M. Delivery of DNA into mammalian cells by receptor-mediated endocytosis and gene therapy. Mol Biotechnol. 1995;3(3):237-248.

69. Desai MP, Labhasetwar V, Amidon GL, Levy RJ. Gastrointestinal uptake of biodegradable microparticles: effect of particle size. Pharm Res. 1996;13(12):1838-1845.

70. Seymour LW. Passive tumor targeting of soluble macromolecules and drug conjugates. Crit Rev Ther Drug Carrier Syst. 1992; 9(2):135-187.

71. Jean M, Alameh M, De Jesus D, et al. Chitosan-based therapeutic nanocomplexes for combination gene therapy and gene silencing of in vitro cell lines relevant to type 2 diabetes. Eur J Pharm Sci. 2011; 45(1-2):138-149. Epub November 9, 2011.

72. Chithrani BD, Chan WC. Elucidating the mechanism of cellular uptake and removal of protein-coated gold nanoparticles of different sizes and shapes. Nano Lett. 2007;7(6):1542-1550.

73. Chithrani BD, Ghazani AA, Chan WC. Determining the size and shape dependence of gold nanoparticle uptake into mammalian cells. Nano Lett. 2006;6(4):662-668.

74. Verma A, Stellacci F. Effect of surface properties on nanoparticle-cell interactions. Small. 2010;6(1):12-21.

75. Liu W, Sun S, Cao Z, et al. An investigation on the physicochemical properties of chitosan/DNA polyelectrolyte complexes. Biomaterials. 2005;26(15):2705-2711.

76. Erbacher P, Zou S, Bettinger T, Steffan AM, Remy JS. Chitosan-based vector/DNA complexes for gene delivery: biophysical characteristics and transfection ability. Pharm Res. 1998;15(9):1332-1339.
77. Danielsen S, Strand S, de Lange Davies C, Stokke BT. Glycosaminoglycan destabilization of DNA-chitosan polyplexes for gene delivery depends on chitosan chain length and GAG properties. Biochim Biophys Acta. 2005;1721(1-3):44-54. Epub November 2, 2004.

78. Köping-Höggård M, Mel'nikova YS, Vårum KM, Lindman B, Artursson P. Relationship between the physical shape and the efficiency of oligomeric chitosan as a gene delivery system in vitro and in vivo. $J$ Gene Med. 2003;5(2):130-141.

79. Gao S, Dagnaes-Hansen F, Nielsen EJ, et al. The effect of chemical modification and nanoparticle formulation on stability and biodistribution of siRNA in mice. Mol Ther. 2009;17(7):1225-1233.

80. JiAM, Su D, Che O, et al. Functional gene silencing mediated by chitosan/ siRNA nanocomplexes. Nanotechnology. 2009;20(40):405103.

81. Bishop NE. An Update on Non-clathrin-coated Endocytosis. Rev Med Virol. 1997;7(4):199-209.

82. Huang M, Ma Z, Khor E, Lim LY. Uptake of FITC-chitosan nanoparticles by A549 cells. Pharm Res. 2002;19(10):1488-1494.

83. Center for Biologics Evaluation and Research, US Food and Drug Administration. Guidance for Industry: Considerations for Plasmid DNA Vaccines for Infectious Disease Indications. Rockville, MD; 2007. Available from: http://www.fda.gov/BiologicsBloodVaccines/ GuidanceComplianceRegulatoryInformation/Guidances/Vaccines/ ucm074770.htm. Accessed January 1, 2012.

84. Center for Biologics Evaluation and Research. Guidance for Industry: Considerations for Plasmid DNA Vaccines for Infectious Disease Indications. Rockville, MD: US FDA; 2007. Available from: http://iccvam. niehs.nih.gov/SuppDocs/FedDocs/FDA/FDA_plasdnavac.pdf. Accessed February 23, 2012.

85. Center for Biologics Evaluation and Research. Guidance for FDA Reviewers and Sponsors: Content and Review of Chemistry, Manufacturing, and Control (CMC) Information for Human Gene Therapy Investigational New Drug Applications (INDs). Rockville, MD: US FDA; 2008. Available from: http://www.fda.gov/downloads/BiologicsBloodVaccines/GuidanceComplianceRegulatoryInformation/Guidances/CellularandGeneTherapy/ucm078694.pdf. Accessed February 23, 2012.

86. US Pharmacopeial Convention. Gene therapy products. In: Second Supplement to USP 34-NF 29. Rockville, MD: United States Pharmacopeial; 2011:5135-5158.
International Journal of Nanomedicine

\section{Publish your work in this journal}

The International Journal of Nanomedicine is an international, peerreviewed journal focusing on the application of nanotechnology in diagnostics, therapeutics, and drug delivery systems throughout the biomedical field. This journal is indexed on PubMed Central, MedLine, CAS, SciSearch ${ }^{\circledR}$, Current Contents ${ }^{\circledR} /$ Clinical Medicine,

\section{Dovepress}

Journal Citation Reports/Science Edition, EMBase, Scopus and the Elsevier Bibliographic databases. The manuscript management system is completely online and includes a very quick and fair peer-review system, which is all easy to use. Visit http://www.dovepress.com/ testimonials.php to read real quotes from published authors. 